\title{
Measuring Vulnerability to Multidimensional Poverty
}

\author{
Mauricio Gallardo ${ }^{1}$ (D)
}

Accepted: 9 September 2019 / Published online: 19 September 2019

(c) The Author(s) 2019

\begin{abstract}
A method to measure vulnerability to multidimensional poverty is proposed under a meanrisk behaviour approach. We extend the unidimensional downside mean-semideviation measurement of vulnerability to poverty towards the multidimensional space by incorporating this approach into Alkire and Foster's multidimensional counting framework. The new approach is called the vulnerability to multidimensional poverty index (VMPI), alluding to the fact that it can be used to assess vulnerability to poverty measured by the multidimensional poverty index (MPI). The proposed family of vulnerability indicators can be estimated using cross-sectional data and can include both binary and metric welfare indicators. It is flexible enough to be applied for measuring vulnerability in a wide range of MPI designs, including the Global MPI. An empirical application of the VMPI and its related indicators is illustrated using the official MPI of Chile as the reference poverty measurement. The estimates are performed using the National Socioeconomic Characterisation Survey (CASEN) for the year 2017.
\end{abstract}

Keywords Multidimensional poverty $\cdot$ Vulnerability $\cdot$ Downside risk

JEL Classification I32

\section{Introduction}

The multidimensional nature of welfare has been strongly posited in the economic literature. This trend has spread to various areas of welfare economics and has strong presence in both the distributional analysis (e.g. Kolm 1977; Atkinson and Bourguignon 1982; Maasoumi 1986; Tsui 1995; Decancq and Lugo 2012) and static analysis of poverty (e.g. Anand and Sen 1997; Mukherjee 2001; Tsui 2002; Atkinson 2003a, b; Bourguignon and Chakravarty 2003; Chakravarty and Silber 2008; Asselin 2009; Alkire and Foster 2011; Alkire and Santos 2014; Belhadj and Limam 2012; Bossert et al. 2013). In recent years, this multidimensional perspective has also been extended to the study of poverty dynamics

Mauricio Gallardo

megallardo@ucn.cl

1 Escuela de Ciencias Empresariales, Universidad Católica del Norte, Larrondo 1281, Coquimbo, Chile 
(e.g. Nicholas and Ray 2012; Alkire et al. 2017a; b) and pro-poor growth (e.g. Klasen 2008; Grosse et al. 2008; Berenger and Bresson 2012).

Concerning the analysis of vulnerability to poverty, the unidimensional view continues to prevail in the majority of recently published research (Dutta, Foster and Mishra 2011; Chiwaula et al. 2011; Calvo and Dercon 2013; Gallardo 2013; Klasen and Waibel 2013; Celidoni 2013, 2015; Günther and Maier 2014; Povel 2015; Gallardo 2018; Hohberg et al. 2018, among others). To the best of our knowledge, four attempts to measure vulnerability from a multidimensional perspective have been proposed. Two of these (Feeny and McDonald 2016; OPHI 2018) use the multidimensional poverty index (MPI), which was developed with Alkire and Foster's (2011) counting methodology (AF) as the reference indicator of poverty. The two others (Calvo 2008; Abraham and Kavi 2008) use the MPI proposed by Bourguignon and Chakravarty (2003) and the fuzzy poverty indicator of Cerioli and Zani (1990), respectively, as the reference indicators. In this paper, we introduce a new family of vulnerability to multidimensional poverty indexes (VMPI), which is also referenced in the MPI but differs in several substantial aspects with respect to the previous proposals. This new indicator is developed under a mean-risk behaviour approach, incorporating the downside risk as an essential feature of vulnerability. The proposed indicator extends Gallardo's (2013) unidimensional measurement of vulnerability to poverty towards the multidimensional space in the context of the AF counting methodology. In its design, the downside mean-semideviation is used as the risk parameter for each welfare dimension. To introduce this new measurement and clarify its potential contribution to public policy practices, we first briefly summarise below the current approaches for measuring vulnerability to multidimensional poverty. This will also help introduce the concept of vulnerability to multidimensional poverty for a better understanding of the research question.

One proposal to measure vulnerability to multidimensional poverty was introduced by Calvo (2008). He extended Calvo and Dercon's (2005; 2007) approach of unidimensional vulnerability towards the multidimensional space. According to Calvo and Dercon (2005, $2007,2013)$, vulnerability is understood as 'the threat of future poverty', which is related to both '(a) the likelihood of suffering poverty in the future, and (b) the severity of poverty in such a case' (Calvo and Dercon 2005: 7). Vulnerability as the threat of being poor, in this sense, constitutes a state of defencelessness against possible states of future poverty. Such a threat, in Calvo and Dercon's view, constitutes a welfare loss by itself, regardless of the actual welfare outcome in the future. 'Individuals dread the possibility of future poverty episodes, and they are said to be vulnerable to the extent that poverty cannot be ruled out as a possible scenario. By the same token, their vulnerability is greater when there is a worse danger to fear, when poverty threatens to be more severe' (Calvo and Dercon 2005: 7). In the unidimensional space, these researchers proposed to measure vulnerability to poverty for the $i$ th individual through the following formula: $V U P_{i}=1-E\left[\min \left(y_{i}, z\right) / z\right]^{\alpha}$, $0<\alpha<1$, where $y_{i}$ is the monetary outcome of the $i$ th individual, $z$ is the poverty line and $E[$.$] is the expected value operator. If we notice that the utility function U=y_{i}^{\alpha}$ is implicit in the formula (see Gallardo 2018: 1096), then, under such an approach, we could understand the unidimensional vulnerability as the proportion of expected utility below the poverty line. From such a formulation, this vulnerability approach is extended towards multiple welfare dimensions in the following terms (Calvo 2008: 1011): 'It is this threat of suffering any form of poverty in the future that we will call "vulnerability to multidimensional poverty".'

Inspired by the $V U P_{i}$ definition, to measure vulnerability to poverty in the multidimensional space, Calvo (2008) combines welfare dimensions in which an individual could 
experience poverty, through a Constant Elasticity of Substitution (CES) utility function, in the same way as that in the multidimensional poverty measures proposed by Bourguignon and Chakravarty (2003) and Deutsch and Silber (2005). ${ }^{1}$ Thus, he arrived at the following definition of vulnerability to multidimensional poverty for the $i$ th individual:VMP $P_{i}=1-E\left[\left(\sum_{j=1}^{J} \gamma_{j}\left(\min \left(y_{i j}, z_{j}\right) / z_{j}\right)^{\rho}\right)^{\frac{\alpha}{\rho}}\right]$, where the $\gamma_{j}$ coefficients are the weights for each welfare dimension $j$, such that $\sum_{j=1}^{J} \gamma_{j}=1$ and $\frac{1}{1-\rho} \geq 0$ is the elasticity of substitution between dimensions, whereas $\alpha \in(0,1)$ and $\rho \in[0,1]$. Note that consistent with the $V U P_{i}$ formulation, $V M P_{i}$ could also be interpreted intuitively as the proportion of expected utility below multidimensional poverty.

A second approach to measure vulnerability to multidimensional poverty was proposed by Abraham and Kavi (2008). These researchers introduced a fuzzy measure of vulnerability, which was developed using Cerioli and Zani's (1990) membership function. According to this function, the degree of membership to the set of poor for the $i$ th individual in a given welfare dimension is defined as $\phi_{i}\left(y_{i}\right)=\left(y_{h}-y_{i}\right) /\left(y_{h}-y_{l}\right)$, where $y_{i}$ is the value of the welfare achievement for individual $i$, whereas $y_{h}$ and $y_{l}$ are the highest and lowest values of this welfare variable in the population, respectively. An individual with the highest achievement in the given welfare dimension will have a membership value of zero to the set of poor in such a dimension, whereas an individual with the lowest achievement will have a membership value of one. The poor individuals in a given dimension are identified according to a high level of membership function (those with the maximum value are the absolute poor), whereas the vulnerable individuals are identified according to a chosen vulnerability threshold of the membership function (e.g. 0.7). The headcount ratio of the vulnerable people in each dimension is then computed, and the aggregation over the welfare dimensions is performed using equal weights.

A third approach to measure vulnerability to multidimensional poverty was introduced in the work of Feeny and McDonald (2016), and it was also applied in the assessment performed by Azeem et al. (2017). This approach is basically an application of the unidimensional measure of vulnerability as expected poverty (see e.g. Chaudhuri et al. 2002; Christiansen and Subbarao 2005) to the MPI. Under the expected poverty framework, unidimensional vulnerability is measured as the probability to be poor in the future, conditional to a household's characteristics. Then, by analogy with this concept, Feeny and McDonald (2016) presented a measure of vulnerability to multidimensional poverty as the probability to be multidimensionally poor in the future by using the MPI cross-dimensional cut-off as the reference threshold in order to identify those people who are multidimensionally poor.

Another approach to measure vulnerability to multidimensional poverty as inspired by the MPI is implemented regularly in practice by the Oxford Poverty and Human Development Initiative (OPHI) at the University of Oxford, when they compute the global MPI for the United Nations Development Program. Under the OPHI approach, vulnerability to multidimensional poverty is measured in a framework that is analogous to the unidimensional concept of vulnerability as an extended poverty line (see Gallardo 2018, section 3, subsection 3.1.2., for a summary or Cafiero and Vakis 2006 for details about the extended

\footnotetext{
1 For a detailed analysis of Calvo's (2008) approach to vulnerability to multidimensional poverty, readers can consult the work of Chakravarty (2018, Chapter 6).
} 
poverty line approach). According to the AF counting methodology, a person is identified as multidimensionally poor through two cut-offs. In the first cut-off, people who have a welfare level under a unidimensional threshold $z_{j}$ in each poverty indicator are identified as deprived in such an indicator. Then, a deprivation score for each person is calculated as the weighted sum of the previously identified deprivations in each poverty indicator. Finally, the second cut-off is applied, in which those people who have a deprivation score equal to or greater than a cross-deprivation threshold $k$ are identified as multidimensionally poor. In the Global MPI, the cross-deprivation threshold $k$ is defined in $1 / 3$, that is, every person belonging to a household with a deprivation score equal to or greater than $1 / 3$ is identified as multidimensionally poor. ${ }^{2}$ By contrast, every person with a score between $1 / 5$ and $1 / 3$ is identified as belonging to a band of people who are vulnerable to multidimensional poverty (see OPHI 2018: 88). The logic of this concept of vulnerability is that those who are in a range of poverty thresholds close to the defined multidimensional poverty cut-off are actually at risk of becoming multidimensionally poor. In Calvo's (2008) terms, this means that such people are under the threat of being poor.

At this point, it should be noted that a fundamental difference exists between the concepts of poverty and vulnerability. A person is poor whenever the stochastic process that generates his/her welfare achievements yields a low effective outcome, which, in turn, allows the identification of such a person as poor under certain classification rules (poverty thresholds). In this sense, poverty is an observable and easily verified fact. The only thing we need in order to identify a person as poor is to record whether he/she meets the condition of being under certain poverty thresholds. Vulnerability instead concerns the uncertainty that people face with regard to having a welfare level below such poverty thresholds. That is, unlike poverty, vulnerability is not an effective realisation of the welfare stochastic process; rather, it concerns the risk of being poor, which is not necessarily realised in a state of effective poverty. Thus, as vulnerability concerns only a probable event, not an effective one, it is a phenomenon that is not easy to measure and verify. For public policy purposes, however, knowing not only who are those multidimensionally poor but also those who are at risk of becoming or remaining multidimensionally poor is crucial. Policymakers should make decisions taking into account not only effective poverty but also the uncertainty surrounding people with low welfare achievements in order to prevent future states of poverty.

This paper makes a contribution to the measurement of vulnerability to multidimensional poverty, which shares with previous approaches the concept of vulnerability as the risk of becoming or remaining poor. However, this new approach has some differences with respect to those in previous research. First, the proposed VMPI allows application using cross-sectional data, so this is a practical advantage in comparison to Calvo's (2008) approach, which is only applicable to panel data. Second, unlike Abraham and Kavi's (2008) approach, the VMPI is not only applicable to the welfare dimensions measured with metric or ordinal variables with multiple categories but also to those dimensions measured with binary variables. Third, unlike Feeny and McDonald's (2016) approach, the VMPI is not computed straightforward in a unidimensional way from an aggregate indicator of multiple deprivations. Instead, it is computed multidimensionally, with the risk of being deprived in each welfare indicator being estimated in the first step and the aggregate multidimensional indicator of vulnerability being generated only in the second step. Fourth,

\footnotetext{
2 This is based on the fact that the global MPI is composed of three dimensions, and it is considered sufficient to be deprived in one dimension to be classified as poor (Alkire and Santos 2014).
} 
unlike the OPHI approach, the VMPI includes in the set of vulnerable people not only those non-poor who are at risk of becoming poor but also those who, being already poor, are still at risk of remaining poor. Finally, the distinctive feature of the VMPI compared with the previous multidimensional vulnerability approaches is that it is supported on a mean-risk dominance criterion, which is sensitive to the downside asymmetry (for details on this quality, see Gallardo 2018: 1098). Furthermore, the VMPI is flexible to include both binary and metric welfare indicators, and it could be applied to measure vulnerability in a wide range of multidimensional poverty AF frameworks, including the Global MPI.

In what follows, the proposed measurement framework is presented. Then, we offer an empirical illustration applied to cross-sectional data from Chile in the year 2017 under the official MPI design of this country. We conclude the article with some final remarks.

\section{The Proposed Measurement}

The standard strategy to measure poverty in a population was defined by Sen (1976: 219) as following a biphasic pattern that consists of '(1) identifying the poor among the total population and (2) constructing an index of poverty using the available information on the poor.' The first component is known in the literature as the identification problem, and the second is known as the aggregation problem. The same strategy must be followed to measure vulnerability to poverty.

In the unidimensional approach to poverty, the identification problem is usually solved in one cut-off through the poverty line $z$. A household is classified as poor whenever its focal welfare variable (consumption or income) is less than $z$. In the multidimensional approach, by contrast, two cut-offs are usually required (see Alkire and Foster 2011; Bourguignon and Chakravarty 2003; Bossert et al. 2013): one to determine who is welfare deprived in each dimension (unidimensional identification) and another to determine who must be identified as poor in the multidimensional space (multidimensional identification). A similar two-cutoff strategy is applied to address the identification problem for the VMPI.

The first cut-off is performed through a generalisation of the procedure proposed by Gallardo (2013) for unidimensional vulnerability, which is explained in the following scenario. Consider a population of $N$ individuals with sub-indices $i=1,2, \ldots, N$. Suppose we have defined $M$ of welfare's dimensions, which are denoted by the sub-indices $m=1,2, \ldots, M .^{3}$ The welfare of each person over a period of time $t$ can be represented by the vector $\mathrm{y}_{i}=\left(y_{i 1}, \ldots, y_{i M}\right)$, where each $y_{i m} \in \mathfrak{R}_{+}$is a random variable of the welfare outcome for person $i$ in the focal attribute $m$. The array of all $\mathrm{y}_{i}$ vectors in the population forms the random matrix $Y$ of $N$ rows and $M$ columns.

The random variables in vector $\mathrm{y}_{i}$ could be metrical or categorical-binary. All binary variables in a $y_{i}$ vector follow a Bernoulli probabilistic process. In the event of deprivation, the binary variable $y_{i m}$ is equal to zero; in the presence of the welfare attribute, it is equal to one. If there are metrical variables in vector $\mathrm{y}_{i}$, their probability density functions are unknown to the researcher. Thus, in the presence of metrical variables, the joint distribution $f\left(y_{i 1}, \ldots, y_{i M}\right)$ is also unknown. However, we are always in a position to reasonably estimate $\mu_{i}=\left(\mu_{i 1}, \ldots, \mu_{i M}\right)$ and $\mathrm{r}_{i}=\left(r_{i 1}, \ldots, r_{i M}\right)$, which are the vectors of the expected values of $\mathrm{y}_{i}$ and the risk parameter vector, respectively, where each element $r_{i m} \in \mathfrak{R}_{+}$such that $r_{i m} \leq \mu_{i m}$ represents the risk for $y_{i m}$ to deviate below the expected value $\mu_{i m}$.

${ }^{3}$ In what follows, we use the terms 'welfare dimensions' and 'welfare indicators' interchangeably. 
We assume that an individual's preferences can be reasonably represented by the utility function $U_{i}\left(\mu_{i 1}, \ldots, \mu_{i M} ; r_{i 1}, \ldots, r_{i M}\right)$, with partial derivatives $\frac{\partial U_{i}}{\partial \mu_{i m}}>0, \frac{\partial U_{i}}{\partial r_{i m}}<0, \forall i, \forall m$. Therefore, for any two random vectors $\mathrm{y}_{i}, \mathrm{y}_{j}$, the following mean-risk dominance relation holds ( $>$ denotes strict preference), with at least one inequality strict for some $m$ :

$$
\mathrm{y}_{i}>\mathrm{y}_{j} \Leftrightarrow \mu_{i m} \geq \mu_{j m} \wedge r_{i m} \leq r_{j m}, \quad \forall m .
$$

We further assume that the policymaker defines a vector of social preferences over the mean-risk relationships through the following vector of risk aversion coefficients: $\gamma=\left(\gamma_{1}, \ldots, \gamma_{M}\right), \gamma_{m} \in(0,1] \forall m$. There are two reasons why it is reasonable for each $\gamma_{m}$ to be bounded in the interval $(0,1]$. The first one, as pointed out by Gallardo (2013), concerns the preference rationality. Because of risk aversion preferences, we have $\gamma_{m}>0, \forall m$. However, it is also reasonable to expect that the policymaker and society will value the gains in expected welfare at least as much as avoiding the risk losses. Therefore, $\gamma_{m} \leq 1, \forall m$. The second argument by Ogryczak and Ruszczynski $(1999,2001)$ is of a statistical nature. They demonstrated that for the unidimensional relation $y_{i m}>y_{j m} \Leftrightarrow\left(\mu_{i m}-\gamma_{m} r_{i m}>\mu_{j m}-\gamma_{m} r_{j m}\right)$, the $\gamma_{m}$ values bounded in the considered interval between zero and one lead to a rational preference ordering, which is consistent with the second-order stochastic dominance criterion. Then, the assumption regarding the vector $\gamma$ allows us to compare any two random vectors $\mathrm{y}_{i}$ and $\mathrm{y}_{j}$ according to the following mean-risk dominance criterion:

$$
y_{i}>y_{j} \Leftrightarrow\left(\mu_{i m}-\gamma_{m} r_{i m} \geq \mu_{j m}-\gamma_{m} r_{j m}\right) \forall m \wedge \exists\left(\mu_{i m}-\gamma_{m} r_{i m}>\mu_{j m}-\gamma_{m} r_{j m}\right)
$$

In the context of this preference framework, we extend Gallardo's (2013) definition of unidimensional vulnerability to establish the following unidimensional identification criteria:

Criterion 1 (unidimensional identification) Let $z_{m}$ be the vulnerability threshold for the welfare focal attribute $y_{m}$. Then, person $i$ is vulnerable to poverty in dimension $m$ whenever $\mu_{i m}-\gamma_{m} r_{i m} \leq z_{m}^{\mathrm{v}}$. If $y_{m}$ is a metrical variable, $z_{m}^{\mathrm{v}}$ is equal to $z_{m}$, the poverty line in the focal attribute $m$ under certainty. If $y_{m}$ is a binary variable, $z_{m}^{\mathrm{v}}$ is equal to a probability threshold.

The variable $z_{m}^{v}$ is equal to a probability threshold for the binary variables because the expected value for such a type of variable is a probability. For these variables, the poverty threshold is equal to one under certainty and takes the value of zero when a household is poor in that focal dimension of welfare. However, for any Bernoulli variable, the expected value is in the range $(0,1)$ and is equal to the probability of this variable being equal to one. Thus, the value $\mu_{i m}-\gamma_{m} r_{i m}$ is also defined in the interval $(0,1)$ for binary variables because of $\gamma_{m} \in(0,1]$ and $r_{i m} \leq \mu_{i m}$.

As the relevant risk is asymmetric in nature, we follow Gallardo (2013) in taking the standard downside mean-semideviation as the risk parameter in each dimension $m$. This parameter, which is widely used in financial research literature on risk assessment (see e.g. Estrada 2002), is defined as follows:

$$
\sigma_{i m}^{-}=\sqrt{E\left\{\min \left[\left(y_{i m}-\mu_{i m}\right), 0\right]^{2}\right\}} .
$$


Then, for each Bernoulli variable, the standard downside mean-semideviation takes the following specific form ${ }^{4}$ :

$$
\sigma_{i m}^{-}=\sqrt{p_{i m}^{2}\left(1-p_{i m}\right)}
$$

where $p_{i m}$ is the probability of being non-poor for person $i$ in the dimension $m$, which, in this case, is also equal to the expected value of $y_{i m}$. That is, for the Bernoulli welfare variables, the criterion 1 has the following specific form: an individual $i$ is vulnerable to poverty in the dimension $m$ whenever $p_{i m}-\gamma_{m} \sqrt{p_{i m}^{2}\left(1-p_{i m}\right)} \leq z_{m}^{\mathrm{v}}$.

From this point, we now move to the AF method (Alkire and Foster 2011; Alkire et al. 2015, Chapter 5) to solve the problems of multidimensional identification and aggregation in the summary multidimensional vulnerability measures.

Let $z^{\mathrm{v}}=\left(z_{1}^{\mathrm{v}}, \ldots, z_{M}^{\mathrm{v}}\right)$ be the vector of vulnerability thresholds for the relevant $M$ focal welfare attributes. Let $g_{i m}^{\mathrm{v} 0}$ be an indicator function that has a value of one when person $i$ is vulnerable in the dimension $m$, and let $w=\left(w_{1}, \ldots, w_{M}\right)$ be the weighting vector for the $M$ welfare dimensions such that $\sum_{m=1}^{M} w_{m}=1$. Then, the vulnerability score for household $i$ is defined as the weighted sum:

$$
s_{i}^{V}=\sum_{m=1}^{M} w_{m} g_{i m}^{\mathrm{v} 0} .
$$

With this vulnerability score, the individuals vulnerable to multidimensional poverty can be identified according to the following criterion:

Criterion 2 (multidimensional identification) The person $i$ is vulnerable to poverty in the multidimensional space $\mathbb{R}^{M}$ whenever $s_{i}^{V} \geq k$, where $k$ is the multidimensional poverty threshold.

Regarding the choice of the multidimensional cut-off $k$, we recall that this is a controversial point in the literature (see Atkinson 2003a, b). An intuitive and straightforward solution will be the so-called union method (e.g. Bourguignon and Chakravarty 2003; Bossert et al. 2013), which consists of identifying as multidimensionally poor those people who are deprived in at least one welfare dimension. This solution makes sense in line with the poverty assessment in the space of capabilities, given that the functioning, according to Sen (2003), has an intrinsic value. Another solution is the intersection method (e.g. Layte et al. 2000), which consists of classifying as multidimensional poor those people who are

\footnotetext{
4 The formula in (4) follows from the calculation of the standard semi-variance for these types of variables, where the event of being non-poor in the dimension $m$ takes the value of one with a probability of $p_{i m}$. Then, the semi-variance of the Bernoulli variable $y_{i m}$ is obtained as follows: $E\left\{\min \left[\left(y_{i m}-\mu_{i m}\right), 0\right]^{2}\right\}=0^{2} p_{m}+\left(0-p_{m}\right)^{2}\left(1-p_{m}\right)=p_{m}^{2}\left(1-p_{m}\right)$.
} 
deprived in all dimensions. The standard AF methodology (Alkire and Foster 2011) follows an intermediate solution in which the multidimensional cut-off is somewhere between these two extremes, including the union method and the intersection method as special cases.

As is well known in the literature, the choice of $k$ involves some practical issues regarding the number of people who are going to be classified as poor (see e.g. Alkire and Foster 2011; Dotter and Klasen 2017 for another view). However, for the VMPI computation, the $k$ cut-off is a given parameter that depends of the reference MPI design in which we are estimating the risk of being poor.

Once those individuals who are vulnerable to multidimensional poverty are identified, the next step is to solve the aggregation problem of quantifying in a summary measure the amount of multidimensional vulnerability existing in a population. The simplest multidimensional vulnerability measure will be the headcount ratio, which is the percentage of people who are vulnerable to multidimensional poverty in a population. This measure can be defined as follows:

$$
V^{H}=\frac{1}{N} \sum_{i=1}^{N} I_{s_{i}^{V} \geq k}
$$

where $I_{s_{i}^{V} \geq k}$ is an indicator function that equals one if person $i$ is vulnerable to multidimensional poverty and otherwise equals zero. Note that $V^{H}$ is the analogue of the headcount ratio $H$ (the percentage of multidimensionally poor people in a population) in the AF MPI framework. The $V^{H}$ measure, as well as the $H$, however, has several limitations, such as the non-compliance of several desirable axioms and its inability to capture the intensity of the experienced vulnerability. To accomplish the task of defining a more general and suitable family of aggregate multidimensional vulnerability measures, we follow a more general procedure, as suggested by Alkire et al. (2015: 173-175), for summarising the cardinal deprivation indicators under the AF method.

We can define the normalised vulnerability gap of order $\alpha$ for person $i$ in the dimension $m$ as follows:

$$
g_{i m}^{\alpha}=g_{i m}^{0}\left(\frac{z_{m}^{\mathrm{v}}-\left(\mu_{i m}-\gamma_{m} r_{i m}\right)}{z_{m}^{\mathrm{V}}}\right)^{\alpha}, \quad \alpha \geq 0 .
$$

Then, we define the following general vulnerability to multidimensional poverty measure of $\alpha$ order, which belongs to the AF family of multidimensional measures and is therefore associated with the FGT (Foster, Greer and Thorbecke 1984) class of poverty measurements:

$$
V^{\alpha}\left(Y, \gamma, \mathrm{z}^{\mathrm{v}}, k\right)=\frac{1}{N} \sum_{i=1}^{N} \sum_{m=1}^{M} w_{m} g_{i m}^{\alpha} I_{s_{i}^{V} \geq k}, \alpha \geq 0 .
$$

For $\alpha=0$, the VMPI as the adjusted headcount ratio (adjusted by the percentage of deprivations to which the vulnerable people are exposed) is obtained. Note also that $V^{0}$ is the analogue of $M_{0}$ (the adjusted headcount ratio) in the MPI framework. We recall that in the MPI framework, $M_{0}$ is the product of two indicators: the headcount ratio $H$ (the share of people who are poor in a population) and the average intensity of deprivation $A$ (the 
average deprivation score among the poor). By analogy, $V^{0}$ is the product of the headcount vulnerability ratio $V^{0}$ (the share of people who are vulnerable in a population) and the average vulnerability intensity $A^{V}$ (the average vulnerability score among the vulnerable people).

In Eq. (8) for $\alpha=1$ and $\alpha=2$, the adjusted multidimensional vulnerability gap $V^{1}$ and the adjusted multidimensional vulnerability quadratic gap $V^{2}$ are obtained, respectively.

According to Alkire et al. (2015), all the AF family measures, as defined in (8), satisfy the following desirable axiomatic properties for a poverty measurement: unidimensional deprivation focus, multidimensional deprivation focus, symmetry, replication invariance, scale invariance, dimensional monotonicity, population subgroup decomposability, dimensional breakdown and weak deprivation rearrangement (see the proofs in Alkire and Foster 2011).

In addition to the above family of vulnerability measurements, we introduce two complementary indicators which could be informative in the context of vulnerability assessment: the vulnerability to poverty ratio $V P R$ and the over-rate of vulnerability headcount ratio $O R V$. The $V P R$ is the quotient between the vulnerability headcount ratio $\left(V^{H}\right)$ and the poverty headcount ratio $(H)$ :

$$
V P R=\frac{V^{H}}{H}
$$

This indicator is important to provide policymakers with complementary information on how many vulnerable people are by each poor person. On the other hand, the $O R V$ is the difference between the vulnerability headcount ratio $\left(V^{H}\right)$ and the poverty headcount ratio $(H)$ :

$$
O R V=V^{H}-H .
$$

This indicator provides policymakers with complementary information on the surplus of multidimensional vulnerability headcount ratio above the poverty headcount ratio.

\section{Empirical Application}

In this section, we illustrate the VMPI estimation by applying this measurement method to a practical case in a country with a middle level of development and where poverty has recently decreased significantly but where vulnerability remains in an important share of the population. In the next subsection, we present a summary of the reference MPI indicator. Then, in the second subsection, we explain in detail our estimation strategy. In the third subsection, we present the used data sources. Next, the main estimation results are discussed. We finish the empirical illustration section with some robustness analyses and comparisons of consistency between our VMPI results with those obtained in two other alternative measures of vulnerability to multidimensional poverty that also take the AFdeveloped MPI as the reference indicator.

\subsection{Reference MPI}

To illustrate the proposed measurement method, we offer an estimate of the VMPI for Chile by using the official MPI of this country as the reference poverty measure. This MPI has already been assessed by the country's specialists with the OPHI's technical support, and it is 
currently regularly estimated in practice to inform Chilean policymakers. Recently, this MPI has been modified; originally consisting of four dimensions, it has been revised to have five dimensions (CASEN 2016). It initially included only the dimensions of education, health, housing, and labour and social security, which are the core dimensions of the indicator. In 2015, an additional dimension of networks and social cohesion was included to capture the deprivations in functioning related to the lack of support networks and social exclusion that people could experience. According to CASEN (2016), this improvement was introduced with the intention to cover the so-called 'missing dimensions', which are often not considered in several MPI designs, including the global MPI. The normative foundation for the inclusion of these five welfare dimensions in the Chilean MPI design is presented in a methodological document (CASEN 2016: 17). In the illustrative example, we estimate the VMPI by using the updated five-dimensional welfare MPI design. However, in one of the robustness exercises, we make a comparison with the previous four-dimensional design.

It must be taken into account that the Chilean MPI was designed particularly for a country with a middle level of development. The case of Chile is interesting for our purposes, as it is a country where poverty has been attenuated but where vulnerability continues to have strong presence. The Chilean MPI design, similar to any other MPI design, has room for improvement. In fact, there exist other MPI design proposals for Chile (Denis et al. 2010; Battiston et al. 2013; Santos and Villatoro 2018). However, for our illustrative purposes, we take the official MPI as given, as its possible criticism is beyond the scope of this article.

Table 1 shows the structure of the reference Chilean MPI in terms of its indicators, their weights and their poverty thresholds. The identification unit of the Chilean MPI is the household. That is, the poverty cut-off in each indicator is defined at the household level. The four basic dimensions (education, health, housing, and labour and social security) have equal weights of 0.225 each, whereas the dimension of networks and social cohesion has a lesser weight of 0.1 . In total, the Chilean MPI has 15 indicators, three for each welfare dimension.

\subsection{Estimation Strategy}

In this illustrative example, all indicators are treated as Bernoulli-type binary variables because by construction, the Chilean MPI only has such a type of welfare indicator. Our identification unit for the VMPI indicator, as well as the identification unit of the Chilean MPI, is the household. Our first step is to obtain an estimate of the mean for each household in each binary indicator of welfare achievement. That is, we must estimate each household's probability of being non-poor in each welfare indicator. To meet this task, for each welfare indicator, we perform a multilevel probit estimation with random intercepts in which the latent variable $y_{i m}^{*}$ is specified as follows:

$$
y_{i j m}^{*}=\beta_{0}+\beta_{1} \mathrm{x}_{i j}+\beta_{2} \mathrm{z}_{j}+u_{j}+e_{i j}
$$

where $\mathrm{x}_{i j}$ is a vector of the household's characteristics, including the household head's characteristics, $\mathrm{z}_{j}$ is a vector of the municipality variables that affect the expected values in each welfare indicator, $\beta_{0}, \beta_{1}$ and $\beta_{2}$ are the vectors of the parameters, $u_{j} \sim N\left(0, \sigma_{j}^{2}\right)$ is a random intercept for each municipality $j$ and $e_{i j} \sim N\left(0, \sigma_{i j}^{2}\right)$ is a specific disturbance at the household level. The multilevel estimation has been used recently in other research on vulnerability to poverty to control for the covariate risk that affects the communities according to their characteristic (e.g. Günther and Harttgen 2009; Mina and Imai 2016). 


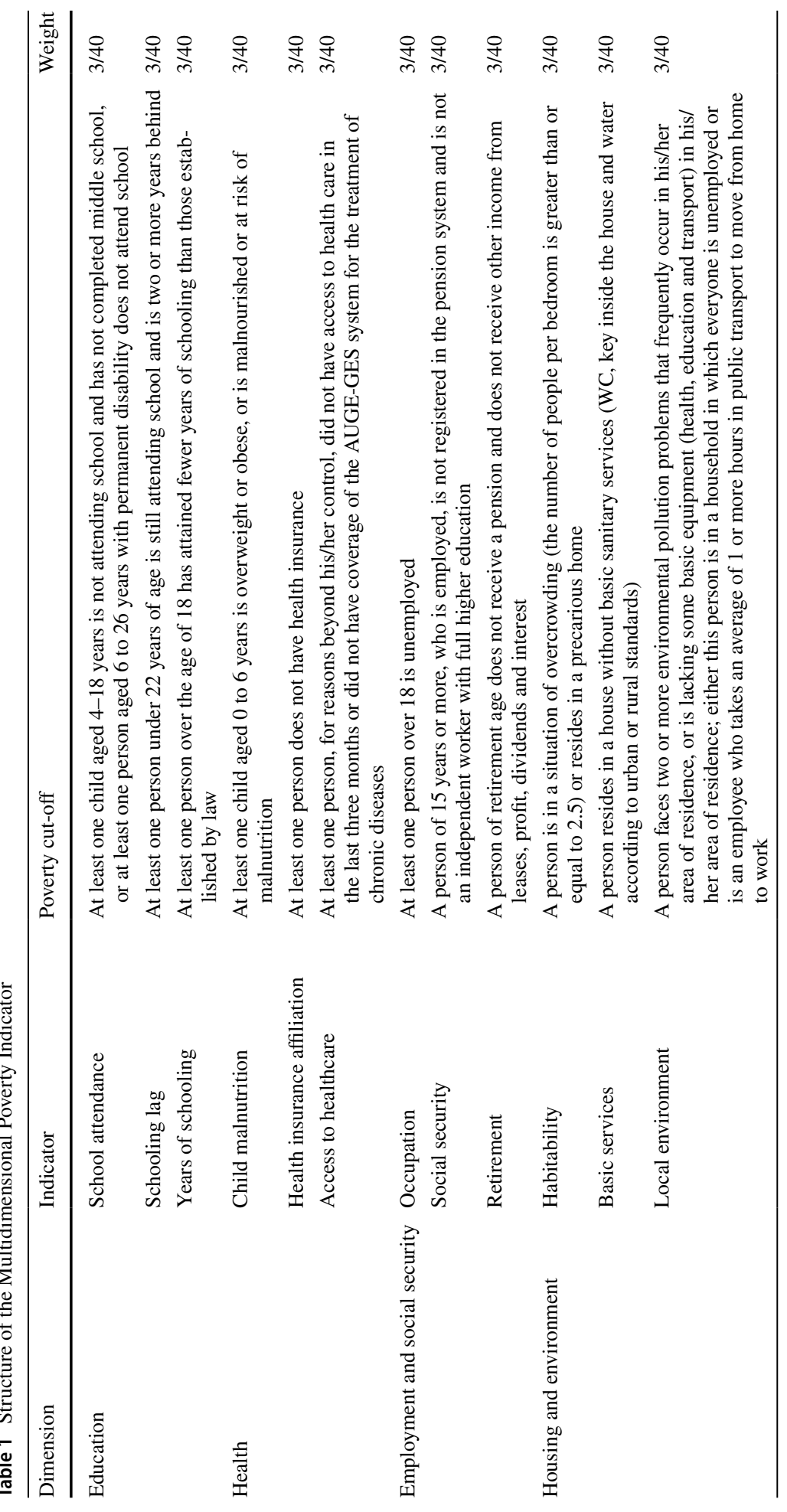




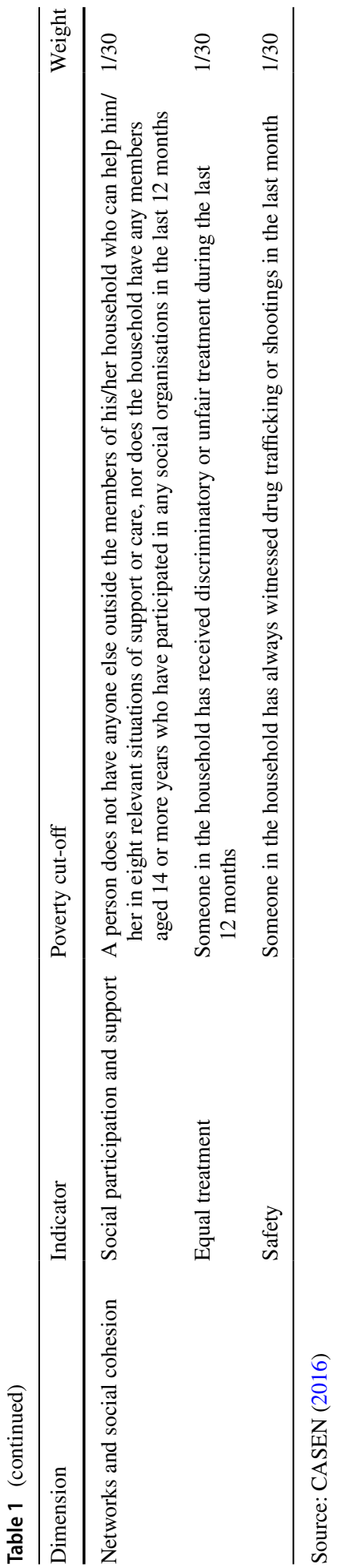

Springer 


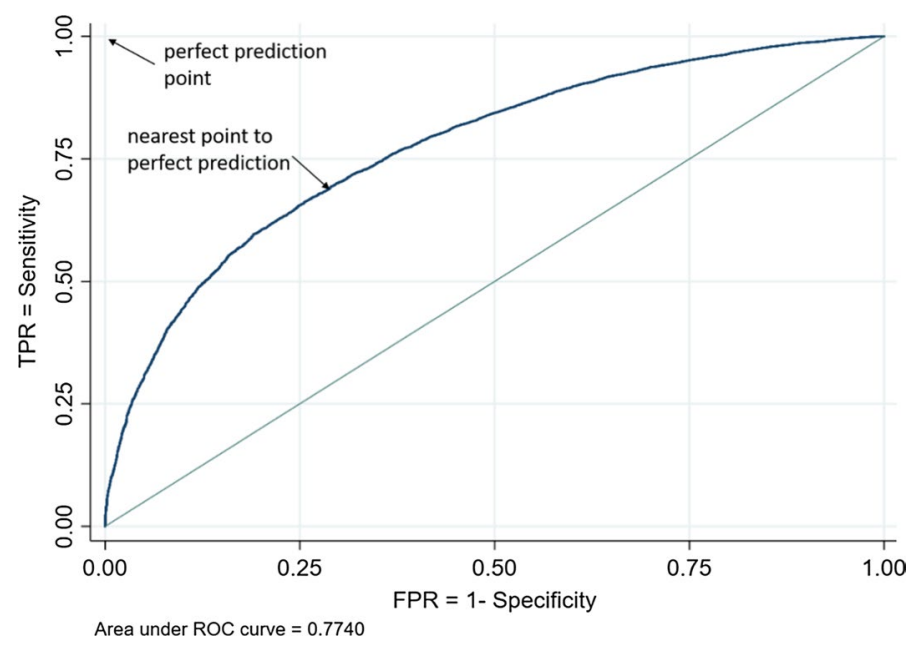

Fig. 1 An ROC curve illustration

In addition to the probit model, we also perform a logistic regression estimation under the same latent variable model specified in (11) but within the framework of logistic probability distribution. As we shall see later, both the probit and logit estimates give similar results, as is the case with other applications. However, we also implement the logit estimates because the logistics probability density function has heavier tails than the Gaussian probability density function, which could be relevant in this context of vulnerability to poverty assessment. Therefore, we should verify whether the differences between these distributions in the tails will not significantly affect the results.

The probit and logit models provide estimates for each probability $p_{i m}$, which, in turn, are estimates of the expected value for each Bernoulli distributed indicator. Then, we also use these probabilities to estimate the standard downside mean-semideviation following the formula defined above in (4). Once we have estimated both the mean and risk parameters for each welfare indicator, we just need define the vulnerability thresholds $z_{m}^{\mathrm{v}}$ and the risk aversion parameters $\gamma_{m}$ to be able to identify the vulnerable households for each indicator following the below rule:

$$
\hat{p}_{i m}-\gamma_{m} \sqrt{\hat{p}_{i m}^{2}\left(1-\hat{p}_{i m}\right)} \leq z_{i m}^{\mathrm{v}},
$$

where $\hat{p}_{i m}$ is an estimate of $p_{i m}$. To avoid arbitrariness in the choice of $z_{m}^{\mathrm{v}}$, following Hohberg et al. (2018), we took advantage of the receiver operating characteristic (ROC) curve analysis.

The ROC curve is illustrated in Fig. 1. It is a useful tool to find the threshold in which a binary predictor performs best, that is, to be as close as possible to the perfect prediction point. In the ROC space, we have in the ordinate axis the true positive rate (TPR) achieved for a binary predictor, against the false positive rate (FPR) in the abscissa axis.

In our framework, the TPR is the ratio between the truly predicted as non-poor people in each welfare indicator and the total of effectively non-poor in the same indicator. The FPR is the ratio between the falsely predicted as non-poor and the total of effectively poor. The ROC curve is set in the ROC space by plotting the achieved TPR and FPR points with a binary predictor for every prediction threshold. The perfect prediction point in the ROC space is found in the coordinates $(0,1)$ in Fig. 1 , in which the TPR equals one and the FPR 
equals zero. The optimal prediction threshold for a binary predictor is then at that point over the ROC curve which is closest to the perfect prediction point (Youden 1950).

In keeping with the usual ROC analysis terminology, the TPR is called the sensitivity of the binary predictor. Meanwhile, the FPR is called 1-specificity, as the complement of the FPR is the true negative rate (in our case, the poor are correctly predicted as poor), which is called specificity. The arrows in the figure indicate the point of perfect prediction in the ROC space and the point of best prediction over the ROC curve. This last point is what determines the choice of the optimal threshold to be predicted as non-poor in each welfare dimension.

The argument that supports the choice of vulnerability thresholds using ROC analysis is that utilising such a threshold maximises the chances of a household being correctly predicted as non-poor in each dimension, given its characteristics. Conversely, those households that are well predicted as non-poor will unlikely be predicted as poor in that dimension; thus, the households that are well predicted as non-poor are those that overcome the relevant risk of being poor in that dimension.

To choose the vulnerability threshold using the ROC curve analysis, we do not use the probabilities $\hat{p}_{i m}$; instead, we directly use the adjusted mean, which is the mean discounting by the downside risk predictor: $\hat{p}_{i m}-\sqrt{\hat{p}_{i m}^{2}\left(1-\hat{p}_{i m}\right)}$, where the risk aversion parameter $\gamma_{m}$ is fixed at one. Then, as we did in selecting the cut-off $k$, we calculate the multidimensional vulnerability indicator for a different $\gamma_{m}$ in a relevant range. The final decision regarding $\gamma_{m}$ at the end of the day will be a question of public choice, which depends on policy goals and social risk aversion preferences. However, performing an assessment of how the vulnerability measures change in a relevant range for such a parameter is necessary prior to making this decision.

As argued previously in Sect. 2, the relevant range for $\gamma_{m}$ should be in the interval $(0,1]$. However, to fix its lower bound relevant to public policy, we must also take into account that a $\gamma_{m}$ close to zero could result in a very few number of vulnerable households; this is because those households with predicted poverty in each welfare dimension could often be fewer than those that are actually poor. It is a well-known fact in the literature on unidimensional vulnerability to poverty that the rate of poverty-induced vulnerability (the rate of those with an expected value of welfare achievement less than the poverty line) could be less than the poverty headcount ratio (see Günther and Harttgen 2009). The explanation for this is that there is a wide range of people who transit across the poverty line. Not all poor people are chronically poor, but there are also transient poor people. Thus, the total number of vulnerable households includes not only those with poverty-induced vulnerability but also those with risk-induced vulnerability.

To determine the $\gamma_{m}$ relevant lower bound, we propose the use of the following practical rule: choose a common $\gamma_{m}$ lower bound for all indicators in that value in which the vulnerability headcount ratio $V^{H}$ is greater than the multidimensional poverty headcount ratio $H$. For instance, in this application, the relevant range of $\gamma_{m}$ was chosen with the lower bound in 0.7 for all dimensions. The option of choosing different risk aversion parameters in the different dimensions is also possible, although it is at the cost of losing parsimony and generating a more complex design. Once the relevant range for the $\gamma_{m}$ parameter is defined, an analysis of the VMPI results in such a range should be performed, with the aim of deciding the choice of a unique risk aversion parameter $\gamma$, which is more relevant for public policy goals.

To close this subsection, we must caution readers about a practical issue that could emerge when the VMPI is estimated, depending on the particular MPI design referenced. This issue refers to the fact that in several MPI designs, including the Global MPI and the Chilean national MPI, some indicators have a partial reference population, that is, 
indicators whose coverage does not include the entire population. This is another controversial issue regarding the MPI design that has already been discussed in the literature not only for the case of the Global MPI (see e.g. Dotter and Klasen 2017) but also in the context of the nationals MPI design in Latin America (Santos 2019). For instance, in the case of the Chilean MPI, the reference population for the child malnutrition indicator only includes those households with children between 0 and 6 years old. Likewise, the reference population for the retirement indicator only includes those households with older adults. In such cases, households that are outside the reference population are identified as nondeprived by definition. In the same way, for the VMPI estimations, those households that are outside the reference population in each welfare indicator must be identified as nonvulnerable by definition. Therefore, the probit and logit models should be performed only with those households belonging to the reference population in each indicator. Likewise, only with such reference populations should the ROC analysis be performed when the vulnerability thresholds are chosen.

\subsection{Data Sources}

The Chilean MPI is calculated using the cross-sectional data of the National Socioeconomic Characterisation Survey (CASEN). This survey has been periodically conducted by the Chilean Ministry of Social Development since 1990, initially in triennial form and then on a biannual basis since 2009. This household survey has national coverage, and it is representative of all regions and the majority of Chilean municipalities. The purpose of the survey is to gather relevant information for assessing the socio-economic situation of Chilean households. The CASEN household survey has a complex sample design stratified by conglomerates, also called segments (sections and blocks), which correspond to the primary sampling units. These conglomerates were formed by adhering to different grouping criteria, both in terms of limit and size. They correspond to groups of dwellings located in geographical areas defined by limits of streets, passages or agglomerations of private dwellings formed from one or more populated entities.

In 2017, the CASEN managed to interview 70,948 households with a total of 216,439 people. After the dataset was filtered for missing values in some indicators, a final sample of 67,820 households and 214,321 people was obtained. Table 10 in the Appendix shows the statistical summary of the missing data. ${ }^{5}$

For the VMPI estimation, we use the 2017 CASEN. In addition, we use the data from the Population Census of Chile of $2017 .{ }^{6}$ The reason why we also utilise the census data is that we perform a multilevel econometric estimation, with the household in the first level and the municipality in the second level. For the household level, we use the CASEN data. However, the explanatory variables at the municipality level are taken from the census data because the CASEN does not provide aggregate variables at the municipality level with statistical significance for all units at the second level. In this way, we exploit the complementarity of information from both data sources. The CASEN and the Population Census are fully coherent in 2017 , as both sources provide information for the same year. Table 2 shows the descriptive statistics of the data from both sources used in the

\footnotetext{
5 The raw data to compute the Chilean MPI, as well as the official Stata codes to filter the data and compute the MPI indicators, are publicly available (see CASEN 2017, for the Stata code).

6 The data of the Population Census of Chile of 2017 are also available by request.
} 
Table 2 Descriptive statistics of the data used in the estimates

\begin{tabular}{|c|c|c|c|c|}
\hline Indicator & Observations & Mean & $\begin{array}{l}\text { Stand- } \\
\text { ard error }\end{array}$ & $\begin{array}{l}\text { Coefficient of } \\
\text { variation }(\%)\end{array}$ \\
\hline $\begin{array}{l}\text { Indicators of achievement at the individual } \\
\text { level (equal to one if non-deprived) }\end{array}$ & Individuals & & & \\
\hline Non-deprived in school attendance & 206,572 & 0.9673 & 0.0014 & 0.1412 \\
\hline Non-deprived in schooling lag & 206,572 & 0.9695 & 0.0013 & 0.1331 \\
\hline Non-deprived in years of schooling & 206,572 & 0.6810 & 0.0044 & 0.6415 \\
\hline Non-deprived in child malnutrition & 206,572 & 0.9318 & 0.0019 & 0.2031 \\
\hline Health insurance affiliation & 206,572 & 0.9392 & 0.0018 & 0.1941 \\
\hline Access to healthcare & 206,572 & 0.9584 & 0.0014 & 0.1452 \\
\hline Occupation & 206,572 & 0.8796 & 0.0023 & 0.2564 \\
\hline Social security & 206,572 & 0.6558 & 0.0037 & 0.5657 \\
\hline Retirement & 206,572 & 0.8911 & 0.0020 & 0.2230 \\
\hline Habitability & 206,572 & 0.7872 & 0.0036 & 0.4595 \\
\hline Basic services & 206,572 & 0.9376 & 0.0017 & 0.1827 \\
\hline Local environment & 206,572 & 0.9011 & 0.0025 & 0.2770 \\
\hline Social participation and support & 206,572 & 0.9358 & 0.0019 & 0.2082 \\
\hline Equal treatment & 206,572 & 0.8637 & 0.0033 & 0.3773 \\
\hline Safety & 206,572 & 0.8671 & 0.0050 & 0.5806 \\
\hline Explanatory variables at the household level & Households & & & \\
\hline Household head's years of schooling & 67,820 & 10.80 & 0.0560 & 0.5188 \\
\hline Household head's age & 67,820 & 53.20 & 0.1797 & 0.3378 \\
\hline Household head-woman & 67,820 & 0.42 & 0.0030 & 0.7162 \\
\hline Household size & 67,820 & 3.07 & 0.0117 & 0.3799 \\
\hline Household with a rural location & 67,820 & 0.13 & 0.0032 & 2.5635 \\
\hline Household head-indigenous & 67,820 & 0.08 & 0.0018 & 2.2039 \\
\hline Dependence rate & 67,820 & 2.20 & 0.0244 & 1.1082 \\
\hline Explanatory variables at the municipality level & Census population & & & \\
\hline Percentage of indigenous population & Target population & 12.8 & & \\
\hline Average years of schooling & Target population & 11.9 & & \\
\hline $\begin{array}{l}\text { Percentage of people working in the mining } \\
\text { sector }\end{array}$ & Target population & 1.4 & & \\
\hline $\begin{array}{l}\text { Percentage of people working in the manufac- } \\
\text { turing sector }\end{array}$ & Target population & 6.4 & & \\
\hline $\begin{array}{l}\text { Percentage of people working in the agricul- } \\
\text { tural sector }\end{array}$ & Target population & 6.0 & & \\
\hline
\end{tabular}

VMPI estimates. In this table, the MPI indicators are reversed; they are presented in terms of achievements and not in terms of deprivation. Furthermore, in our probit and logit estimations, the outcome variable is equal to one when a household is non-deprived in such a welfare indicator.

At the household level, the following explanatory socio-demographic variables were included: household head's years of schooling, age, ethnicity and gender; household size in terms of persons; household location (rural/urban); and the dependency rate in the 


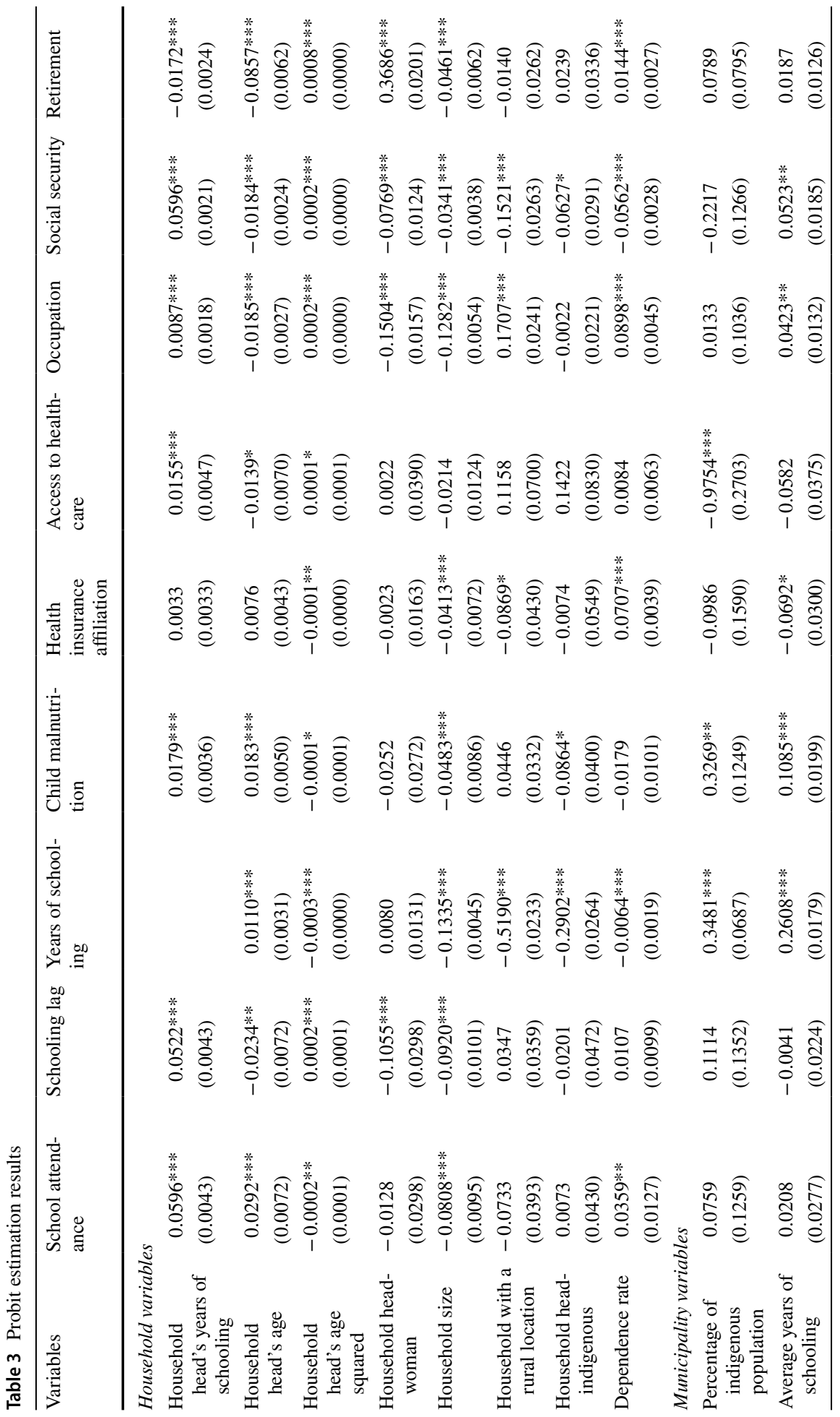




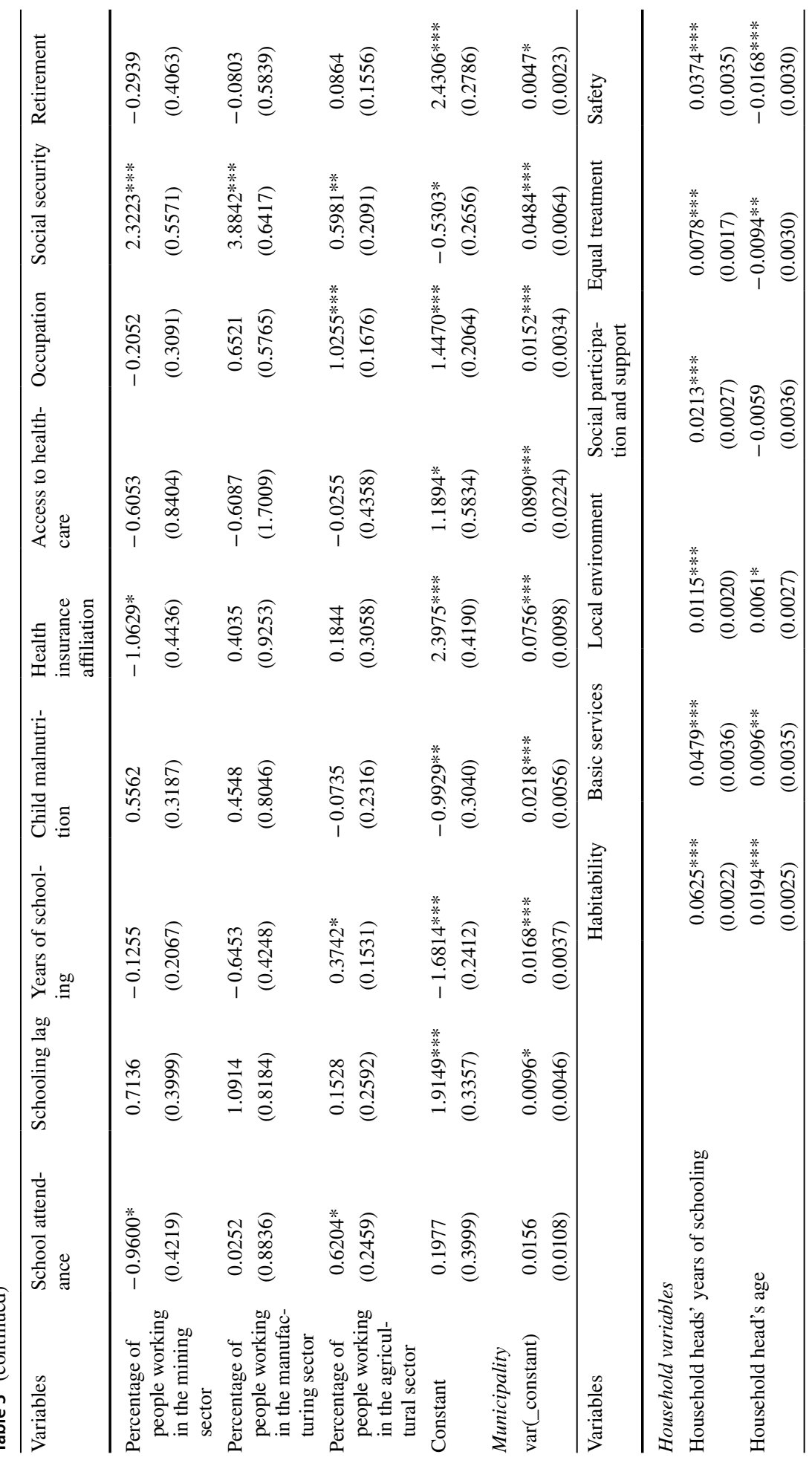




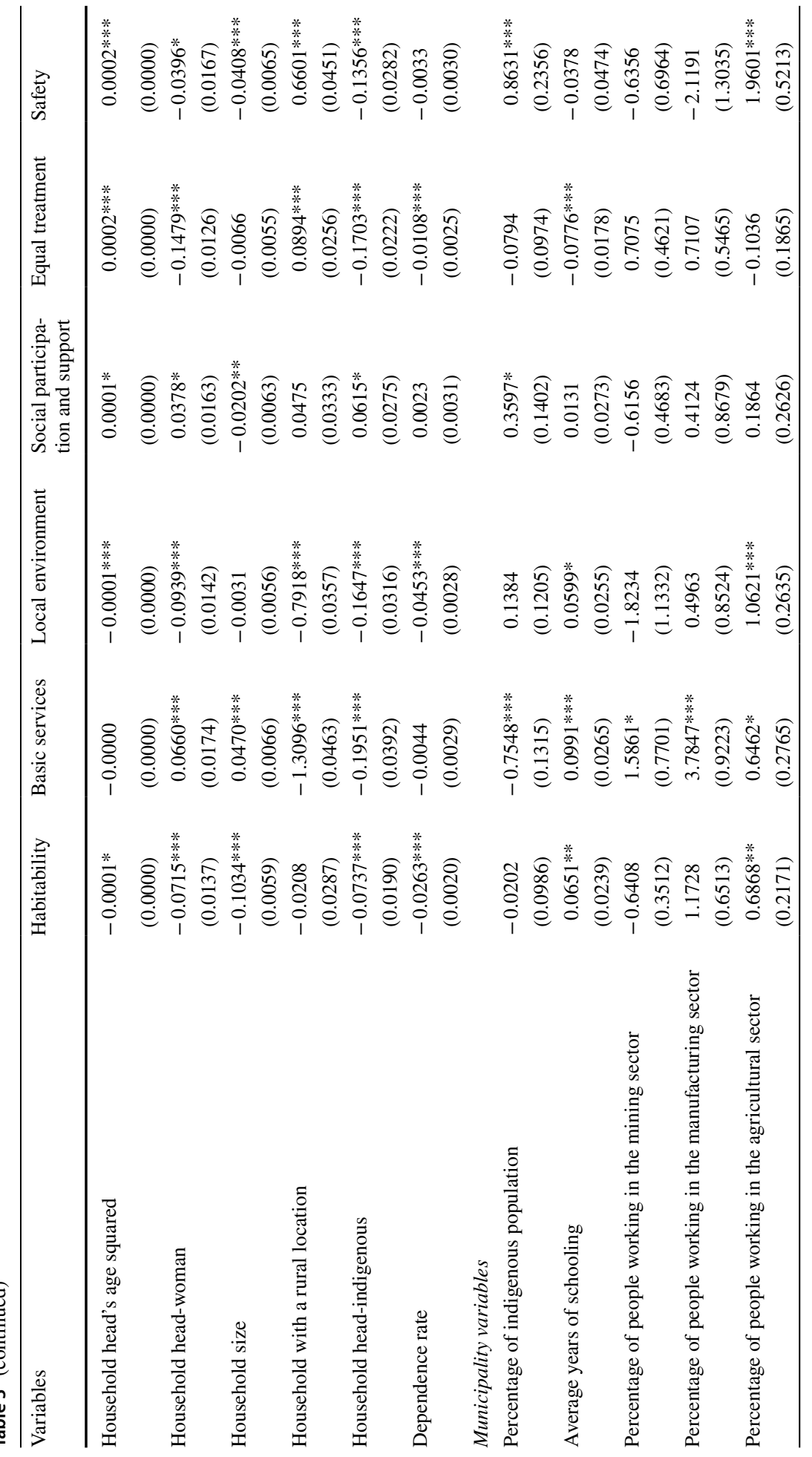




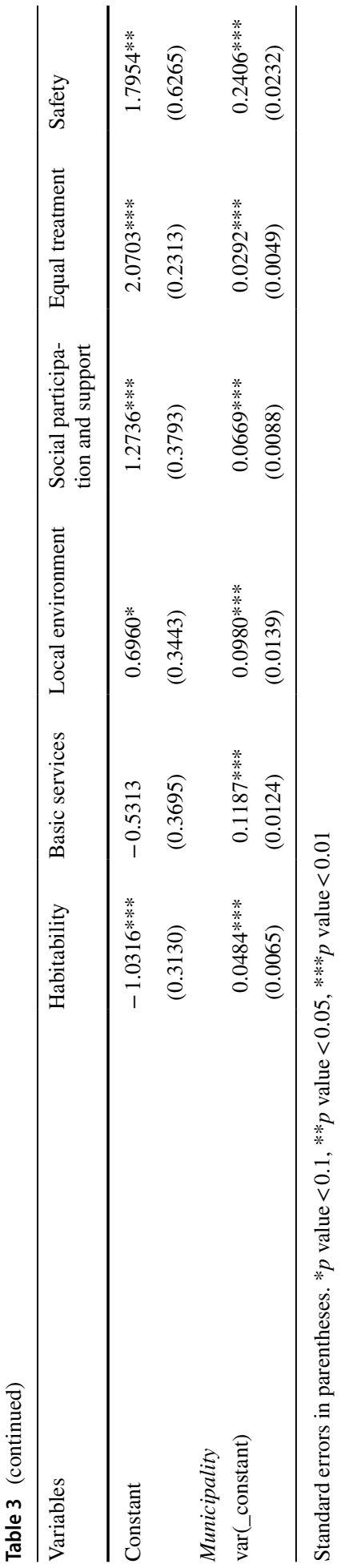

Springer 


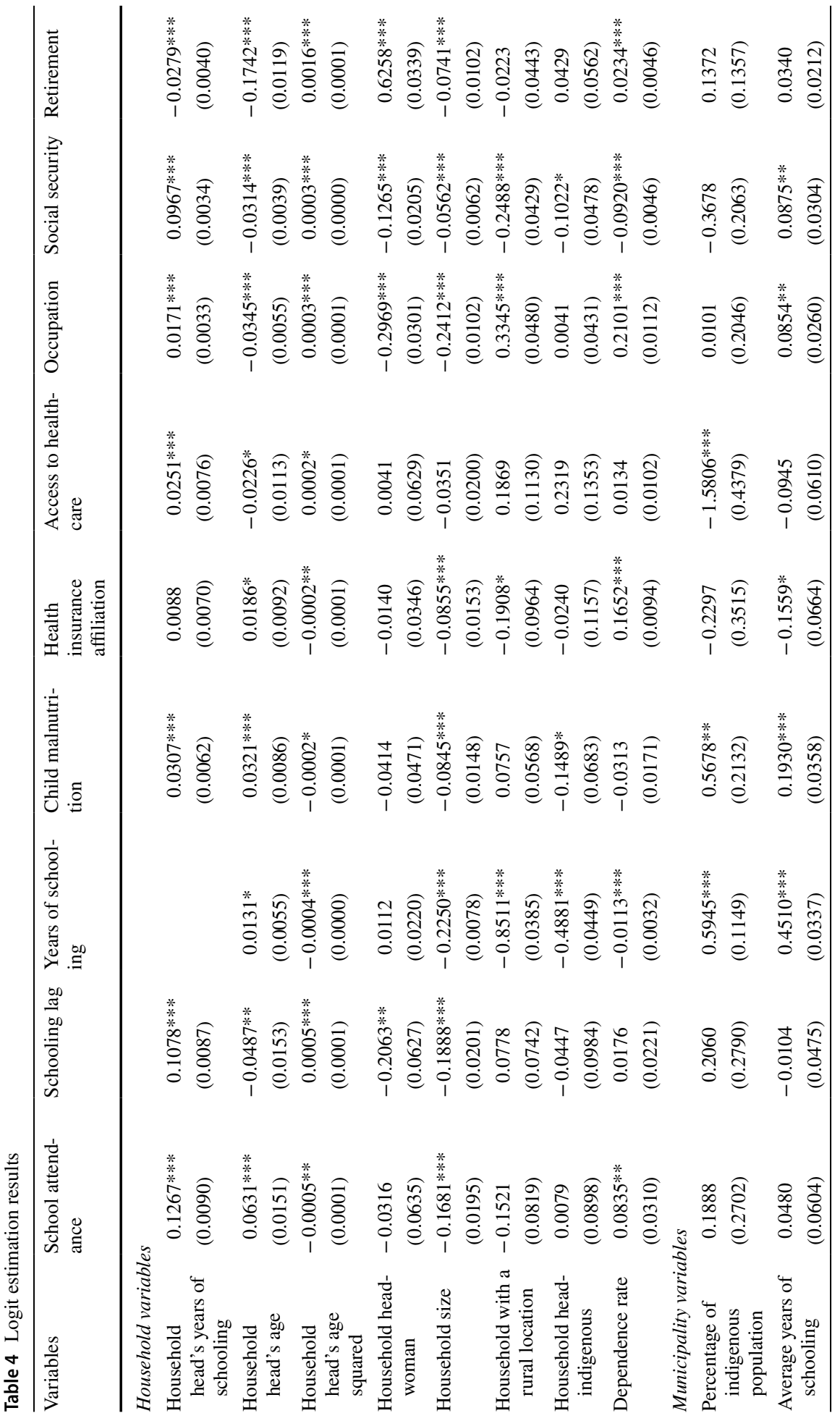




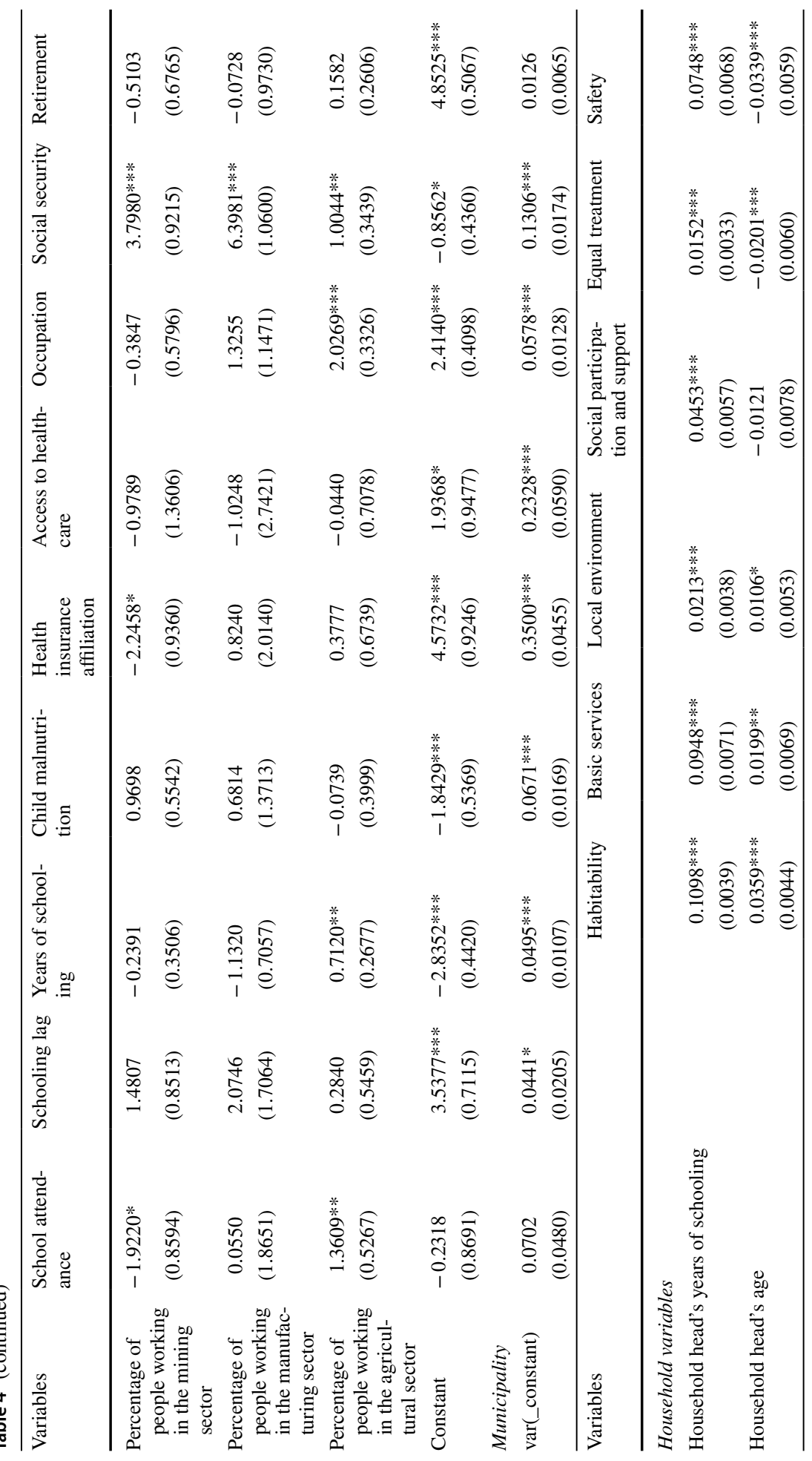




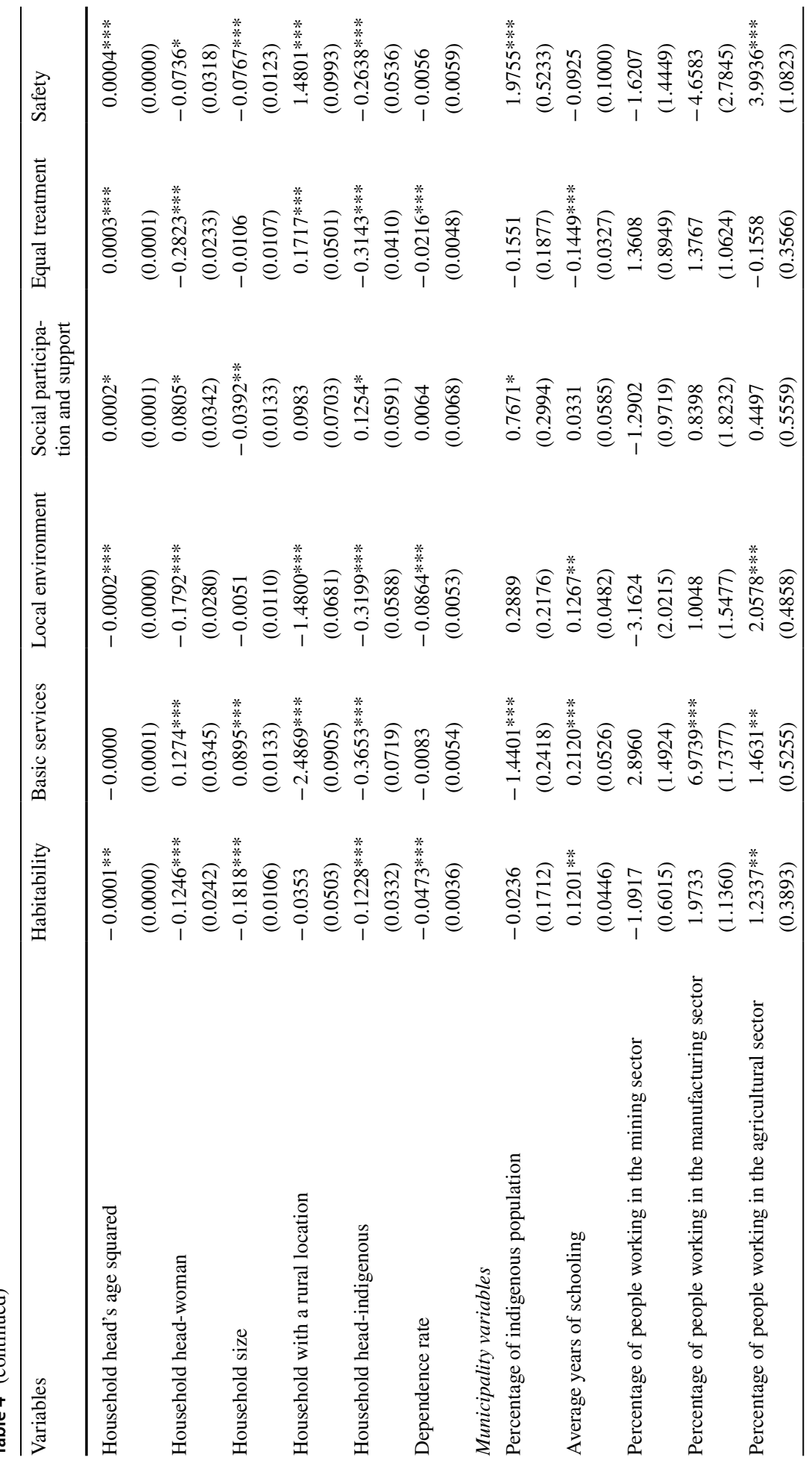




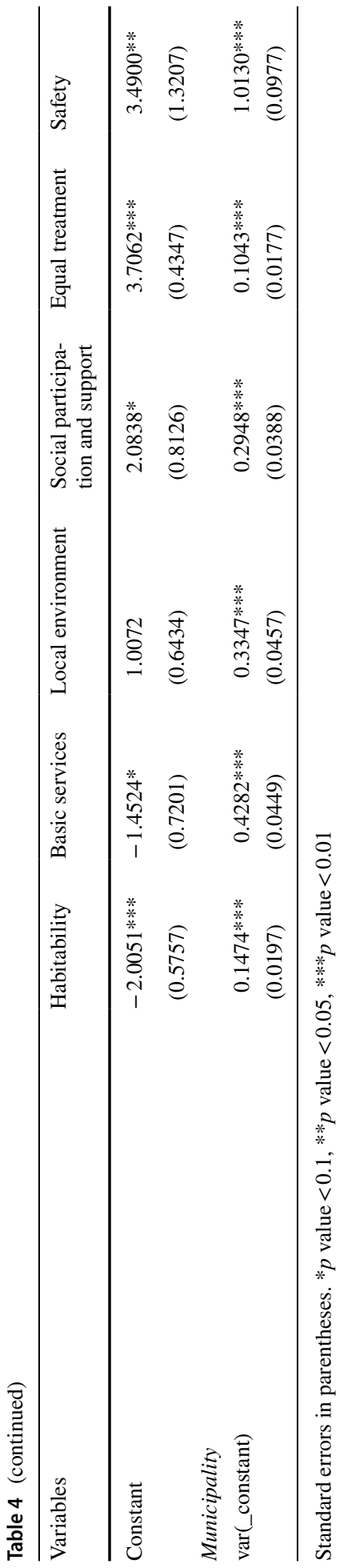

Springer 
Table 5 Vulnerability thresholds for each welfare indicator

\begin{tabular}{lll}
\hline Indicators & $\begin{array}{l}\text { Using probit } \\
\text { estimates }\end{array}$ & $\begin{array}{l}\text { Using logit } \\
\text { estimates }\end{array}$ \\
\hline School attendance & 0.725 & 0.734 \\
Schooling lag & 0.716 & 0.723 \\
Years of schooling & 0.290 & 0.295 \\
Child malnutrition & 0.416 & 0.421 \\
Health insurance affiliation & 0.721 & 0.722 \\
Access to healthcare & 0.166 & 0.166 \\
Occupation & 0.606 & 0.613 \\
Social security & 0.248 & 0.248 \\
Retirement & 0.315 & 0.323 \\
Habitability & 0.448 & 0.455 \\
Basic services & 0.652 & 0.665 \\
Local environment & 0.608 & 0.614 \\
Social participation and support & 0.714 & 0.717 \\
Equal treatment & 0.576 & 0.577 \\
Safety & 0.627 & 0.627 \\
\hline
\end{tabular}

household (the ratio of dependent people to healthy adults of working age). At the municipality level, the following explanatory variables were included: the average educational level in the municipality, the percentage of indigenous population and three variables to control for the municipality's productive structure.

\subsection{Main Results}

Tables 3 and 4 present the econometric results for the probit and logit estimates. We found that the variables of the household head human capital (schooling and age) have a positive effect on the probability of obtaining a welfare outcome above poverty in the majority of the dimensions. We also found that the probability of being non-poor in each welfare indicator is usually linked to other household characteristics, such as the gender of the household head, the household size, the rural location and the dependency rate. With the exception of the habitability indicator, all the random intercepts of the municipalities were found to be statistically significant in both the probit and logit estimates. Amongst the municipalities' control variables, the most important one by statistical significance is the average years of schooling.

Table 5 presents the vulnerability thresholds in each dimension obtained through the ROC curve analysis. As we can see, there is no a single vulnerability threshold to predict non-deprived households in each dimension; instead, such a threshold depends on the particular characteristics of the risk that households experience in each welfare indicator. Note also that although the chosen vulnerability thresholds by the ROC analysis are similar for both the probit and logit estimates, the logit estimates tend to identify slightly higher vulnerability thresholds, given the differences between the Gaussian and logistic distributions in the tails.

To understand how we proceeded to choosing the risk aversion parameter, we observe the results presented in Table 6 . In this table, we offer the results of the vulnerability 


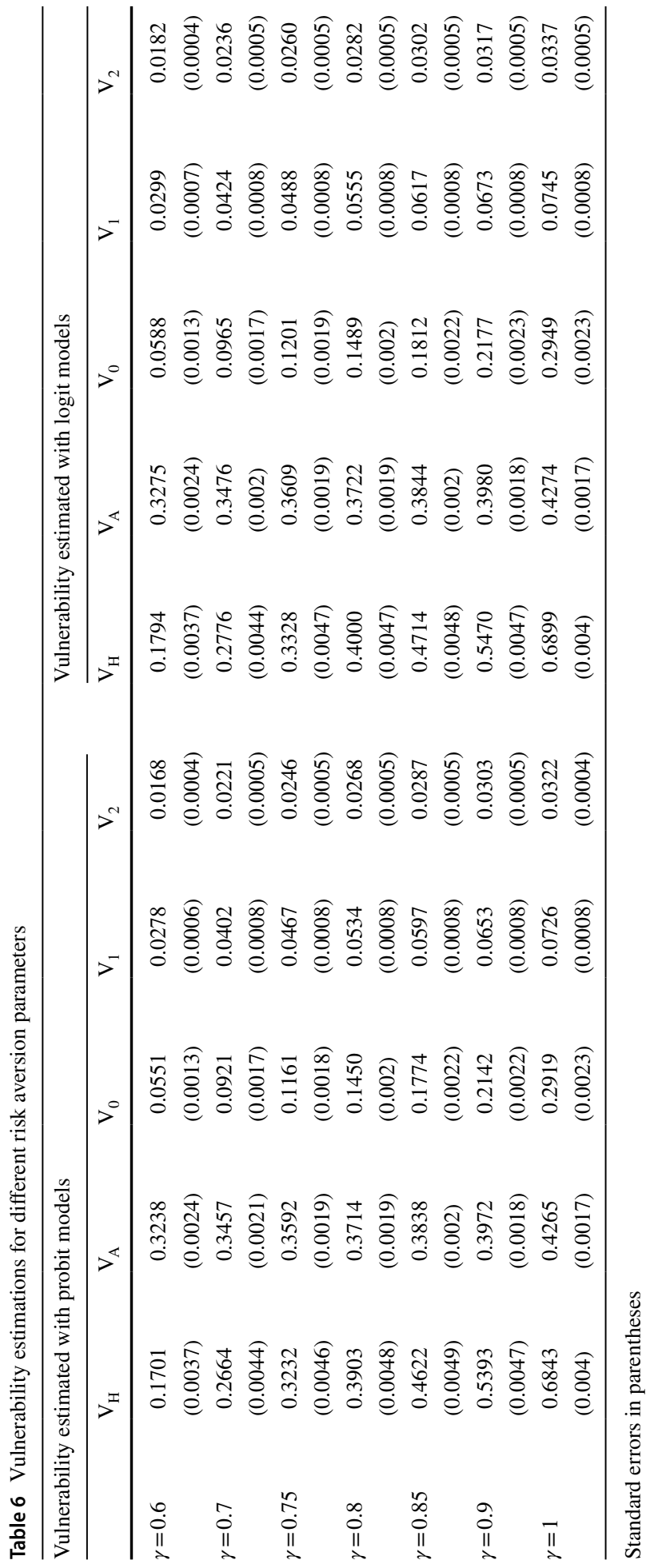


Table 7 Main results and comparisons for different multidimensional cut-offs

\begin{tabular}{|c|c|c|c|c|c|}
\hline & $H-V^{H}$ & $A-A^{V}$ & $M_{0}-V^{0}$ & $V^{1}$ & $V^{2}$ \\
\hline \multicolumn{6}{|l|}{ Poverty } \\
\hline $\mathrm{k}=0.15$ & $\begin{array}{c}0.4438 \\
(0.0044)\end{array}$ & $\begin{array}{c}0.2163 \\
(0.0009)\end{array}$ & $\begin{array}{c}0.0960 \\
(0.0011)\end{array}$ & & \\
\hline $\mathrm{k}=0.225$ & $\begin{array}{c}0.2070 \\
(0.0036)\end{array}$ & $\begin{array}{c}0.2783 \\
(0.0011)\end{array}$ & $\begin{array}{c}0.0576 \\
(0.0011)\end{array}$ & & \\
\hline $\mathrm{k}=0.3$ & $\begin{array}{c}0.0774 \\
(0.0021)\end{array}$ & $\begin{array}{c}0.3435 \\
(0.0015)\end{array}$ & $\begin{array}{c}0.0266 \\
(0.0007)\end{array}$ & & \\
\hline \multicolumn{6}{|c|}{ Vulnerability estimated with probit models } \\
\hline $\mathrm{k}=0.15$ & $\begin{array}{c}0.5673 \\
(0.0044)\end{array}$ & $\begin{array}{c}0.3110 \\
(0.0017)\end{array}$ & $\begin{array}{c}0.1765 \\
(0.0019)\end{array}$ & $\begin{array}{c}0.0627 \\
(0.0008)\end{array}$ & $\begin{array}{r}0.0306 \\
(0.0004)\end{array}$ \\
\hline $\mathrm{k}=0.225$ & $\begin{array}{c}0.3903 \\
(0.0048)\end{array}$ & $\begin{array}{c}0.3714 \\
(0.0019)\end{array}$ & $\begin{array}{c}0.1450 \\
(0.002)\end{array}$ & $\begin{array}{c}0.0534 \\
(0.0008)\end{array}$ & $\begin{array}{r}0.0268 \\
(0.0005)\end{array}$ \\
\hline $\mathrm{k}=0.3$ & $\begin{array}{c}0.2584 \\
(0.0042)\end{array}$ & $\begin{array}{c}0.4319 \\
(0.002)\end{array}$ & $\begin{array}{c}0.1116 \\
(0.002)\end{array}$ & $\begin{array}{c}0.0423 \\
(0.0008)\end{array}$ & $\begin{array}{r}0.0217 \\
(0.0005)\end{array}$ \\
\hline \multicolumn{6}{|c|}{ Vulnerability estimated with logit models } \\
\hline $\mathrm{k}=0.15$ & $\begin{array}{c}0.5800 \\
(0.0043)\end{array}$ & $\begin{array}{c}0.3117 \\
(0.0017)\end{array}$ & $\begin{array}{c}0.1808 \\
(0.0019)\end{array}$ & $\begin{array}{c}0.0650 \\
(0.0008)\end{array}$ & $\begin{array}{c}0.0321 \\
(0.0005)\end{array}$ \\
\hline $\mathrm{k}=0.225$ & $\begin{array}{c}0.4000 \\
(0.0047)\end{array}$ & $\begin{array}{c}0.3722 \\
(0.0019)\end{array}$ & $\begin{array}{c}0.1489 \\
(0.002)\end{array}$ & $\begin{array}{c}0.0555 \\
(0.0008)\end{array}$ & $\begin{array}{r}0.0282 \\
(0.0005)\end{array}$ \\
\hline $\mathrm{k}=0.3$ & $\begin{array}{c}0.2655 \\
(0.0043)\end{array}$ & $\begin{array}{c}0.4323 \\
(0.0019)\end{array}$ & $\begin{array}{c}0.1148 \\
(0.002)\end{array}$ & $\begin{array}{c}0.0440 \\
(0.0008)\end{array}$ & $\begin{array}{r}0.0229 \\
(0.0005)\end{array}$ \\
\hline
\end{tabular}

Standard errors in parentheses

estimates for different risk aversion coefficients. If we take into account that the multidimensional poverty headcount ratio $H$ in Chile is equal to 0.207 in 2017 , then, starting from a $\gamma=0.7$, the vulnerability measure begins to make sense because at that point, the vulnerability headcount ratio $\left(V^{H}=0.2664\right.$ in the probit estimate and $V^{H}=0.2776$ in the logit estimate) is greater than the poverty headcount ratio $H=0.207$. The next step is to choose the risk aversion parameter which is more suitable for public policy goals. For this illustrative example, we have chosen $\gamma=0.8$, which we assess to be more suitable for Chile not only because of its poverty level but also because with $\gamma=0.8$, the Chilean VMPI is more consistent with other vulnerability to multidimensional poverty measures, as we will show later.

Table 7 shows the main results for the multidimensional poverty and VMPI estimates for three different multidimensional cut-offs. According to the official MPI design, the multidimensional cut-off in Chile is $k=0.225$, which is consistent with deprivation in one of the core dimensions. In addition to performing the calculations for the official cut-off, we also computed the VMPI measures for two other cut-offs that may be relevant for public policy decisions. These two cut-offs are $k=0.3$ and $k=0.15$. For $k=0.3$, the household is deprived in one more core indicator above the official cutoff, whereas in $k=0.15$, the household is deprived in one less core indicator below the official multidimensional cut-off. Likewise, $k=0.15$ would be setting a threshold to identify the vulnerable to multidimensional poverty according to the OPHI approach, in the sense that those households with a deprivation score $0.15 \leq k<0.225$ cannot be 
identified as multidimensionally poor, but they are at risk of becoming multidimensionally poor. That is, they become poor if they become deprived in one more core welfare indicator.

At the official $k=0.225,20.7 \%$ of Chileans are multidimensionally poor, whereas $39 \%$ are vulnerable to multidimensional poverty according to the probit estimate and $40 \%$ under the logit estimate. Note that the probit and logit estimates provide similar VMPI results. However, the logit estimates tend to identify a greater number of vulnerable people, as the logistic probability density function has heavier tails than the Gaussian probability density function. It also draws attention to the fact that the VMPI estimates are quite as precise as those of the MPI, on the basis of the standard error magnitudes.

\subsection{Robustness and Consistency Analysis}

The proposed VMPI has been the subject of several decisions. To construct the multidimensional vulnerability measurements, we have made decisions on the indicator weights, the multidimensional poverty cut-off and the risk aversion parameters $\gamma_{m}$. Thus, to ensure that the VMPI is a robust indicator, we must compare if our results are consistent with those we would have obtained with alternative parameterisations. To carry out this analysis, we compare our results with two alternative specifications of the multidimensional cutoff, two alternative specifications of indicator weights, four alternative specifications of the risk aversion parameters and two alternative specifications of the MPI design by removing or adding dimensions.

The alternative specifications are chosen in such a way that they could be judged relevant to public policy. The comparisons by different cut-offs were performed with $k=0.15$, $k=0.225$ and $k=0.3$, whose relevance for public policy was already supported in the previous subsection. The comparisons by weights correspond to the following versions: (1) the official baseline scenario, (2) a scenario with all dimensions having equal weights $(1 / 15$ for each indicator), which is relevant to public policy given that the model of the equally weighted dimension has been supported and used in other well-known multidimensional indicators (Alkire and Santos 2014; Chowdhury and Squire 2006), and (3) a scenario in which the dimension of networks and social cohesion is weighted lower at $0.06(0.06 / 3$, the weight in each indicator for such a dimension), and the core dimensions each increase their weights to 0.235 (0.94/12, the weight in each indicator); this is also relevant for public policies to consider in retrospective because the networks and social cohesion indicators are new, and we can be interested in smoothing more their impact in the MPI time series in order to study poverty and vulnerability dynamics. Comparisons by risk aversion parameters are performed to the following $\gamma$ values: 0.7, 0.75, 0.8, 0.85 and 0.9. As argued previously, the VMPI measures for $\gamma<0.7$ are irrelevant, and also because $\gamma>0.9$, the VMPI measures will be irrelevant for public policies, as it would identify as vulnerable a very large fraction of the population, who could even account for a large share of the middle class (see Table 6). Finally, we perform the following comparisons by alternative MPI design: (1) the official baseline scenario, (2) a scenario with the previous MPI design that has four dimensions (before the networks and social cohesion dimension was included), which is relevant to make comparisons with the past, and (3) a baseline scenario plus the income dimension because in other MPI designs that have been proposed for Chile (Battiston et al. 2013; Santos and Villatoro 2018), the monetary dimension has also been included in the Chilean MPI, which could be justified by the lack of a standard of living indicators in the CASEN survey. 
Table 8 Robustness analysis and pairwise comparisons by region and province

\begin{tabular}{|c|c|c|c|c|c|c|}
\hline & \multicolumn{3}{|c|}{ By region } & \multicolumn{3}{|c|}{ By province } \\
\hline & MPI & VMPI Probit & VMPI Logit & MPI & VMPI Probit & VMPI Logit \\
\hline \multicolumn{7}{|l|}{ Different cut-off } \\
\hline Possible pairwise comparisons & 120 & 120 & 120 & 1378 & 1378 & 1378 \\
\hline Robust pairwise comparisons & 101 & 112 & 110 & 1086 & 1224 & 1226 \\
\hline Ratio of robustness & 0.84 & 0.93 & 0.92 & 0.79 & 0.89 & 0.89 \\
\hline \multicolumn{7}{|l|}{ Different weight } \\
\hline Possible pairwise comparisons & 120 & 120 & 120 & 1378 & 1378 & 1378 \\
\hline Robust pairwise comparisons & 91 & 99 & 101 & 1046 & 1140 & 1147 \\
\hline Ratio of robustness & 0.76 & 0.83 & 0.84 & 0.76 & 0.83 & 0.83 \\
\hline \multicolumn{7}{|l|}{ Different MPI specification } \\
\hline Possible pairwise comparisons & 120 & 120 & 120 & 1378 & 1378 & 1378 \\
\hline Robust pairwise comparisons & 90 & 90 & 91 & 1092 & 1061 & 1068 \\
\hline Ratio of robustness & 0.75 & 0.75 & 0.76 & 0.79 & 0.77 & 0.78 \\
\hline \multicolumn{7}{|l|}{ Different gamma coefficients } \\
\hline Possible pairwise comparisons & & 120 & 120 & & 1378 & 1378 \\
\hline Robust pairwise comparisons & & 107 & 106 & & 1158 & 1175 \\
\hline Ratio of robustness & & 0.89 & 0.88 & & 0.84 & 0.85 \\
\hline
\end{tabular}

We perform the comparisons of the results for the alternative parameterisations and designs by using two types of geographical observation units: regions and provinces. We decompose the VMPI measures for these two geographical subdivisions of Chile (16 regions or 53 provinces), and we determine if the order of the vulnerability measurement by such geographical units remains similar when making changes in the specification of the critical parameters. We implement the strongest possible comparison in terms of ordering random outcomes. We make all possible pairwise comparisons of results between the observation units under different parameterisations by using inference tools that are equivalent to the second-order stochastic dominance comparison criterion. Based on the hypothesis testing with regard to the change in parameters, a pairwise comparison is robust if the statistical order existing in the baseline scenario is the same as that in the alternative scenarios. In keeping with Alkire et al. (2015: 237), the statistical pairwise comparison of the adjusted incidence measures $\left(M_{0}\right.$ in the case of multidimensional poverty whose analogue in the VMPI framework is $V^{0}$ ) using the described tool of statistical inference generates the same type of comparison as the second-order stochastic dominance criterion. This type of comparison may be too stringent and may not hold in some cases. However, if the measurement is robust, it must keep the statistical order in most cases.

Table 8 shows the ratio of robustness for the different comparisons, which is equal to the number of robustness pairwise comparisons divided by the total pairwise comparisons performed. As we can see in the table, the ratio of robustness is high for the four executed robustness exercises. However, in the majority of the cases, the ratio of robustness of the vulnerability measures is even higher than those of the poverty measures.

To conclude this section, we present some results of a consistency analyses. We compare our results with those of other indicators of vulnerability to multidimensional poverty that also take the MPI of the AF methodology as the poverty reference measure. First, we use the same probit econometrical specification presented above to estimate the 
Table 9 Comparison with the alternative measurement

\begin{tabular}{llll}
\hline & $V^{H}(\%)$ & VPR & ORV $(\%)$ \\
\hline VMPI approach (Probit Model) & 39.0 & 1.89 & 18.3 \\
VMPI approach (Logit Model) & 40.0 & 1.93 & 19.3 \\
Feeny and McDonald's approach & 43.0 & 2.08 & 22.3 \\
OPHI approach (adding the poor) & 44.4 & 2.14 & 23.7 \\
\hline
\end{tabular}

probability of being multidimensionally poor, simulating Feeny and McDonald's (2016) approach. That is, we estimate a probit model with the same explanatory variables, but now, the dependent variable is equal to one when the household is multidimensionally poor and equal to zero otherwise. The results of this econometrical estimation are presented in Table 11 in the Appendix. Second, we also use the ROC analysis to define the optimal probability threshold in order to determine the vulnerable households. Finally, we calculate the vulnerability headcount ratio by using Feeny and McDonald's (2016) approach, as the share of people whose probability of being poor is equal to or greater than such an optimal probability threshold. We estimate the Feeny and McDonald's (2016) approach under this procedure to be consistent with our previous estimations. ${ }^{7}$

With respect to the percentage of people who are vulnerable to poverty, as defined under the extended poverty line approach used by the OPHI, we used the threshold of $k=0.15$ to identify them, supported on the criterion indicated previously, according to which such a threshold corresponds to being deprived in one core indicator below the multidimensional cut-off. Therefore, the percentage of vulnerable people under the OPHI approach is equal to $23.7 \%$ (the percentage of multidimensionally poor people between the thresholds $k=0.15$ and $k=0.225$ ). However, to be consistent in the comparison with this third vulnerability indicator, under such an approach, we need to add the poor to the vulnerable ones because unlike the two other approaches, under the OPHI framework, the set of vulnerable people does not include poor people. Table 9 shows the comparison of the vulnerability headcount ratios under the different approaches, as well as the two other related indicators: the vulnerability to poverty ratio $V P R$ and the over-rate of vulnerability headcount ratio $O R V$. We observe that the results are consistent in magnitude across the different approaches. The vulnerability headcount ratios are in the range between $39 \%$ and $44 \%$; all approaches predict about one additional vulnerable person by each poor individual. On the other hand, the over-rate of vulnerability headcount ratio above the poverty headcount ratio is close to $20 \%$.

Although at the aggregate level, vulnerability measures show consistency in magnitude, it is also worth asking whether such measures behave in a similar way in a more disaggregated level. Figure 2 presents a matrix of the scatter plots of poverty and vulnerability headcount ratios for the 53 Chilean provinces estimated with the same measurement approaches presented in Table 9.

In this figure, we observe the high correlations between the headcount ratios of the three different vulnerability approaches we are comparing, as well as their correlation with the multidimensional poverty headcount ratio. In fact, the Pearson correlations of

\footnotetext{
7 In fact, Feeny and McDonald (2016) also estimate a probit model, but they followed the procedure proposed by Chaudhuri et al. (2002) and used fixed probability thresholds of 0.5 and the prevailing poverty headcount ratio instead of an optimized threshold.
} 


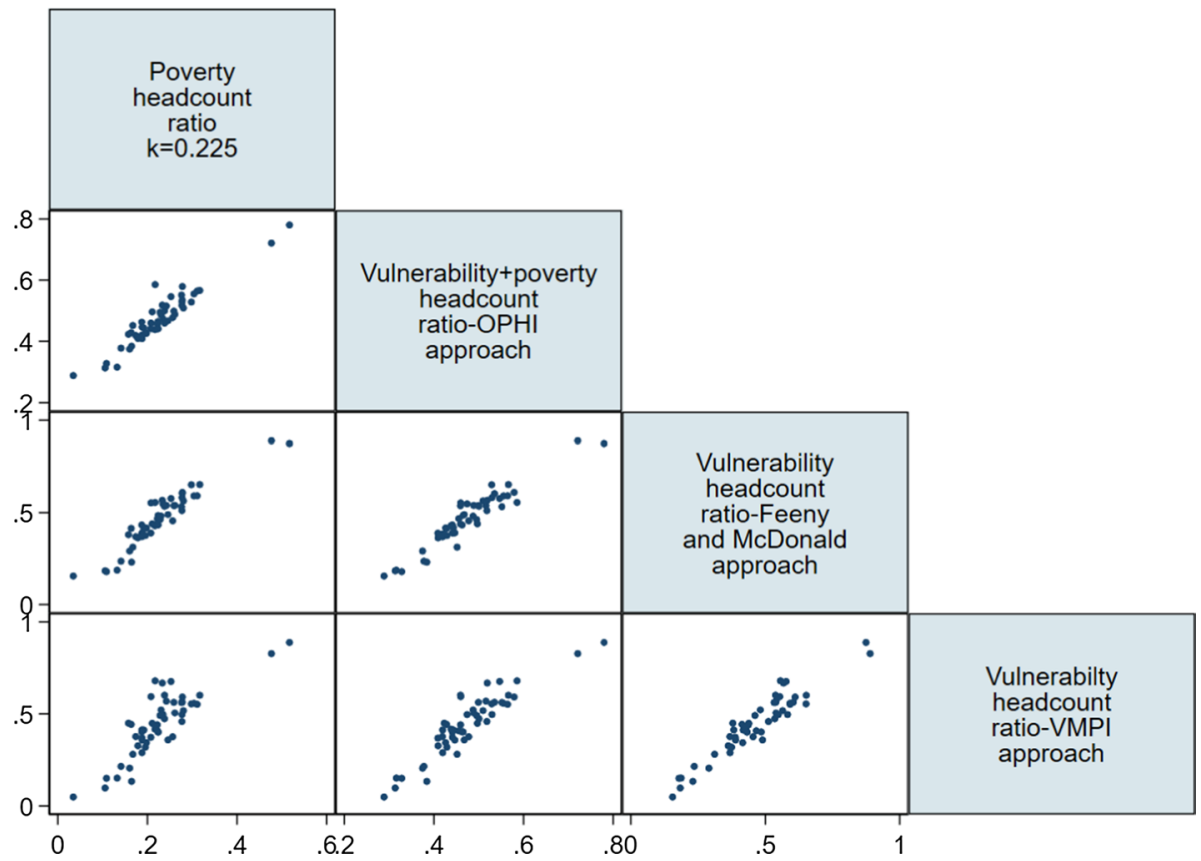

Fig. 2 Multidimensional poverty headcount ratios and vulnerability headcount ratios for Chilean provinces

the vulnerability headcount ratios for the Chilean provinces estimated under the VMPI approach are 0.95 with respect to Feeny and McDonald's (2016) approach, 0.92 with respect to the OPHI approach and 0.85 with respect to the poverty headcount ratio.

It should be warned, however, that the comparative results presented here are only intended to show the consistency between the proposed measurement and similar ones. A comprehensive comparison between the different methods to measure vulnerability to multidimensional poverty is beyond the scope of this article and could be the subject of future research.

\section{Concluding Remarks and Future Research}

A model to measure vulnerability to multidimensional poverty has been proposed in this paper. The introduced measurement is supported on an asymmetric mean-risk dominance criterion for the unidimensional identification of vulnerable individuals in each welfare dimension. Then, the AF method is used in the multidimensional identification stage and in the aggregation phase. The family of multidimensional vulnerability indicators developed here belongs to the AF class of multidimensional measures, so it is also associated with the FGT class of poverty indicators. Consequently, it shares with the AF family and with the FGT class the fulfilment of a broad desirable axiomatic basis for poverty measurements. 
This new VMPI can be estimated with cross-sectional data, which constitutes an advantage in its actual use by policymakers, along with the use of the MPI.

As was shown in the paper, the VMPI is consistent with the two other vulnerability to multidimensional poverty measurements that are also referenced in the MPI under the AF framework. However, it is important to note the differences between the VMPI and these two other indicators. In comparison with Feeny and McDonald's (2016) approach, the VMPI is not applied to the already aggregated indicator of deprivations. That is, the new indicator is not computed straightforward in a unidimensional way from an already aggregated multidimensional measurement. Instead, the VMPI is computed multidimensionally, with the risk of being deprived in each welfare dimension being estimated first and then vulnerability in a multidimensional indicator being aggregated next. This new feature of the VMPI offers both an advantage and a disadvantage compared with Feeny and McDonald's (2016) indicator. The obvious disadvantage is that the VMPI is more complex to estimate and requires more parameterisation decisions. However, it has the advantage of capturing the diversity of the existing risk among the different welfare dimensions. Using the VMPI results in a greater wealth of information, which would otherwise be lost if we estimate straightforward the probability of being multidimensionally poor, as the risk of being multidimensionally poor is not homogeneous and univariate. On the contrary, such a risk is complex, multivariate and very heterogeneous in nature. It is important to note, for instance, the diversity of optimal thresholds of the probability to be deprived in each welfare indicator in the results presented in Table 5. Such thresholds are different even between indicators belonging to the same welfare dimension. This fact indicates the diversity of risk existing among the different MPI components.

With respect to the OPHI approach, the VMPI for his hand has a conceptual difference. In the OPHI concept, the multidimensionally vulnerable and the multidimensionally poor are considered different groups of people. The poor are those effectively identified as poor according to the observed data, whereas the vulnerable are those effectively identified as quasi-poor (close to being poor) also according to the observed data. That is, the OPHI vulnerability measure is not supported on a probability estimate but instead on an observed condition of counting deprivations. Thus, the OPHI approach offers an advantage of parsimony when having a concept of vulnerability that is simple to calculate and interpret. However, the OPHI vulnerability measure, in fact, is another measure of effective poverty, just with a different multidimensional cut-off. The drawback of this concept is that an extended definition of poverty gap is not precisely a risk measure, as it does not incorporate uncertainty as a variability of probable outcomes between the different states of nature. For instance, two households with the same extended poverty gap could be exposed to significantly different levels of risk. This has to do with the fundamental distinction between vulnerability and poverty raised in the introduction of this paper, which is well known in the literature on vulnerability (e.g. Chaudhuri et al. 2002; Ligon and Schechter 2003; Calvo and Dercon 2005, 2007, 2013; Gallardo 2018). Unlike poverty, vulnerability is not a verified fact of a low effective welfare outcome; instead, it is a measure of how risky it is to obtain such a low outcome under uncertainty conditions. 
From the results of this work emerge several avenues for future research. One interesting issue is a deeper understanding of the differences between vulnerability to multidimensional poverty approaches, following the analogy of the Celidoni (2013), who compared the performance of different unidimensional vulnerability approaches. It is also interesting to use the VMPI approach to study the features of risk in different welfare dimensions, which would be useful in providing better guidance to policymakers as they develop public policies that prevent poverty. Another interesting topic for future research will be the study of the dynamics of poverty in different dimensions and their relation to the dynamics of vulnerability over time in different dimensions, which could be investigated with the use of panel data. Of course, these topics do not exhaust the horizon of new research possibilities that may arise in the future from the proposed measurement presented in this article.

Acknowledgements This work was supported by the Chilean National Commission for Scientific and Technological Research (CONICYT), corresponding to the Fondecyt Project No. 11170650 entitled: 'Measuring Vulnerability to Multidimensional Poverty: Methodology and Applications in Latin America'. The author thanks Vicky Pizarro for her help in the data handling, as well as the valuable and constructive comments received in the double blind review process by Social Indicators Research, which substantially contributed to improve the presentation of this work for its final version.

Open Access This article is distributed under the terms of the Creative Commons Attribution 4.0 International License (http://creativecommons.org/licenses/by/4.0/), which permits unrestricted use, distribution, and reproduction in any medium, provided you give appropriate credit to the original author(s) and the source, provide a link to the Creative Commons license, and indicate if changes were made.

\section{Appendix}

See Tables 10 and 11

Table 10 Missing data summary

\begin{tabular}{lccc}
\hline Indicator & Missing values & Observations & Percentage missing \\
\hline School attendance & 0 & 216,231 & $0.00 \%$ \\
Schooling lag & 158 & 216,231 & $0.07 \%$ \\
Years of schooling & 480 & 216,231 & $0.22 \%$ \\
Child malnutrition & 1425 & 216,231 & $0.66 \%$ \\
Health insurance affiliation & 1300 & 216,231 & $0.60 \%$ \\
Access to healthcare & 1590 & 216,231 & $0.74 \%$ \\
Occupation & 0 & 216,231 & $0.00 \%$ \\
Social security & 2797 & 216,231 & $1.29 \%$ \\
Retirement & 0 & 216,231 & $0.00 \%$ \\
Habitability & 718 & 216,231 & $0.33 \%$ \\
Basic services & 119 & 216,231 & $0.06 \%$ \\
Local environment & 447 & 216,231 & $0.21 \%$ \\
Social participation and support & 1068 & 216,231 & $0.49 \%$ \\
Equal treatment & 0 & 216,231 & $0.00 \%$ \\
Physical safety & 0 & 216,231 & $0.00 \%$ \\
\hline
\end{tabular}


Table 11 Econometric results of the probit model estimate (Feeny and McDonald's approach)

\begin{tabular}{|c|c|}
\hline Variables & Coefficients \\
\hline \multicolumn{2}{|l|}{ Household variables } \\
\hline Household head's years of schooling & $\begin{array}{c}-0.1964 * * * \\
(0.0035)\end{array}$ \\
\hline Household head's age & $\begin{array}{c}0.0040 \\
(0.0056)\end{array}$ \\
\hline Household head's age squared & $\begin{array}{c}-0.0002^{* * *} \\
(0.0000)\end{array}$ \\
\hline Household head-woman & $\begin{array}{c}0.0361 \\
(0.0254)\end{array}$ \\
\hline Household size & $\begin{array}{l}0.3341 \text { *** } \\
(0.0103)\end{array}$ \\
\hline Household with rural location & $\begin{array}{l}0.9731 \text { *** } \\
(0.0499)\end{array}$ \\
\hline Household head-indigenous & $\begin{array}{l}0.2645^{* * *} \\
(0.0468)\end{array}$ \\
\hline Dependence rate & $\begin{array}{l}0.0115 * * \\
(0.0044)\end{array}$ \\
\hline \multicolumn{2}{|l|}{ Municipality variables } \\
\hline Percentage of indigenous population & $\begin{array}{l}0.5712 \text { *** } \\
(0.1597)\end{array}$ \\
\hline Average years of schooling & $\begin{array}{c}-0.1159 * * * \\
(0.0305)\end{array}$ \\
\hline Percentage of people working in the mining sector & $\begin{array}{r}-0.2935 \\
(0.7735)\end{array}$ \\
\hline Percentage of people working in the manufacturing sector & $\begin{array}{l}-.2324 * * * \\
(1.0498)\end{array}$ \\
\hline Percentage of people working in the agricultural sector & $\begin{array}{c}-1.7378^{* * *} \\
(0.3193)\end{array}$ \\
\hline Constant & $\begin{array}{c}0.8468 \\
(0.4344)\end{array}$ \\
\hline \multicolumn{2}{|l|}{ Municipality } \\
\hline var(_constant) & $\begin{array}{l}0.1126^{* * *} \\
(0.0157)\end{array}$ \\
\hline
\end{tabular}

Standard errors in parentheses. * $p$ value $<0.1, * * p$ value $<0.05, * * * p$ value $<0.01$

\section{References}

Abraham, R., \& Kavi, K. S. (2008). Multidimensional poverty and vulnerability. Economic and Political Weekly, 43(20), 79-87.

Alkire, S., Apablaza, M., Chakravarty, S., \& Yalonetzky, G. (2017a). Measuring chronic multidimensional poverty. Journal of Policy Modeling, 39, 983-1006.

Alkire, S., \& Foster, J. (2011). Counting and multidimensional poverty measurement. Journal of Public Economics, 95(7-8), 476-487.

Alkire, S., Foster, J., Seth, S., Santos, M., Roche, J., \& Ballón, P. (2015). Multidimensional poverty measurement and analysis. Oxford: Oxford University Press. 
Alkire, S., Roche, J., \& Vaz, A. (2017b). Changes over time in multidimensional poverty: Methodology and results for 34 countries. World Development, 94, 232-249.

Alkire, S., \& Santos, M. E. (2014). Measuring acute poverty in the developing world: Robustness and scope of the multidimensional poverty index. World Development. https://doi.org/10.1016/j.world dev.2014.01.026.

Anand, S., \& Sen, A. (1997). Concepts of human development and poverty: A multidimensional perspective. New York: UNDP.

Asselin, L.-M. (2009). Analysis of multidimensional poverty. Dordrecht: Springer.

Atkinson, A. B. (2003a). Multidimensional deprivation. Contrasting social welfare and counting approaches. Journal of Economic Inequality, 1, 51-65.

Atkinson, A. (2003b). Multidimensional deprivation. Contrasting social welfare and counting approaches. Journal of Economic Inequality, 1, 51-65.

Atkinson, A., \& Bourguignon, F. (1982). The comparison of multidimensional distributions of economic status. Review of Economic Studies, 49, 183-201.

Azeem, M., Mugera, A., \& Schilizzi, S. (2017). Vulnerability to multi-dimensional poverty: An empirical comparison of alternative measurement approaches. The Journal of Development Studies. https://doi. org/10.1080/00220388.2017.1344646.

Battiston, D., Cruces, G., Lopez-Calva, L. F., Lugo, M. A., \& Santos, M. E. (2013). Income and beyond: Multidimensional poverty in six Latin American countries. Social Indicators Research. https://doi. org/10.1007/s11205-013-0249-3.

Belhadj, B., \& Limam, M. (2012). Unidimensional and multidimensional fuzzy poverty measures: New approach. Economic Modelling, 29, 995-1002.

Berenger, V., \& Bresson, F. (2012). On the 'pro-poorness' of growth in a multidimensional context. Review of Income and Wealth, 58(3), 457-480.

Bossert, W., Chakravarty, S., \& D’Ambrosio, C. (2013). Multidimensional poverty and material deprivation with discrete data. Review of Income and Wealth, 59(1), 29-43.

Bourguignon, F., \& Chakravarty, S. (2003). The measurement of multidimensional poverty. Journal of Economic Inequality, 1(1), 25-49.

Cafiero, C., \& Vakis, R. (2006). Risk and vulnerability considerations in poverty analysis: Recent advances and future directions. Social protection discussion paper 0610, World Bank.

Calvo, C. (2008). Vulnerability to multidimensional poverty: Peru, 1998-2002. World Development, 36(6), 1011-1020.

Calvo, C., \& Dercon, S. (2005). Measuring individual vulnerability. University of Oxford: Department of Economics discussion paper series no. 229, University of Oxford.

Calvo, C., \& Dercon, S. (2007). Vulnerability to poverty. CSAE working paper 2007-03.

Calvo, C., \& Dercon, S. (2013). Vulnerability to individual and aggregate poverty. Social Choice and Welfare, 41, 721-740.

CASEN. (2016). Metodología de medición de pobreza multidimensional con entorno y redes. Serie Documentos Metodológicos Casen, $N^{\circ} 32$.

CASEN. (2017). Programación de medida de pobreza multidimensional con entorno y redes. Serie Documentos Metodológicos Casen, $N^{\circ} 33$.

Celidoni, M. (2013). Vulnerability to poverty: An empirical comparison of alternative measures. Applied Economics, 45(12), 1493-1506.

Celidoni, M. (2015). Decomposing vulnerability to poverty. Review of Income and Wealth, 61(1), 59-74.

Cerioli, A., \& Zani, S. (1990). A fuzzy approach to the measurement of poverty. In C. Dagum \& M. Zenga (Eds.), Income and wealth distribution, inequality and poverty. Studies in contemporary economics. Berlin: Springer.

Chakravarty, S. (2018). Analyzing multidimensional well-being: A quantitative approach. Hoboken: Wiley.

Chakravarty, S. R., \& Silber, J. (2008). Measuring multidimensional poverty: The axiomatic approach. In N. Kakwani \& J. Silber (Eds.), Quantitative approaches to multidimensional poverty measurement (pp. 192-209). New York: Palgrave Macmillan.

Chaudhuri, S., Jalan, J., \& Suryahadi, A. (2002). Assessing household vulnerability to poverty from crosssectional data: A methodology and estimates from Indonesia. Department of Economics discussion paper series (vol. 102), Columbia University.

Chiwaula, L., Witt, R., \& Waibel, H. (2011). An asset-based approach to vulnerability: The case of smallscale fishing areas in Cameroon and Nigeria. Journal of Development Studies, 47(2), 338-353.

Chowdhury, S., \& Squire, L. (2006). Setting weights for aggregate indices: An application to the commitment to development index and human development index. Journal of Development Studies, 42(5), 761-771. 
Christiansen, L., \& Subbarao, K. (2005). Toward an understanding of vulnerability in rural Kenya. Journal of African Economies, 14(4), 540-558.

Decancq, K., \& Lugo, M. (2012). Inequality of wellbeing: A multidimensional approach. Economica, 79, 721-746.

Denis, A., Gallegos, F., \& Sanhueza, C. (2010). Medición de Pobreza Multidimensional en Chile. Universidad Alberto Hurtado, Unpublished manuscript. https://dds.cepal.org/infancia/guia-para-estimarla-pobreza-infantil/bibliollgrafia/capitulo-II/Denis Angela - Gallegos Francisca - Sanhueza Claudia (2010) Medicion de la Pobreza Multidimensional en Chile.pdf.

Deutsch, J., \& Silber, J. (2005). Measuring multidimensional poverty: An empirical comparison of various approaches. Review of Income and Wealth, 51(1), 145-174.

Dotter, C., \& Klasen, S. (2017). The multidimensional poverty index: Achievements, conceptual and empirical issues. Poverty, equity and growth-discussion paper no. 233. Göttingen: Courant Research Centre Poverty, Equity and Growth.

Dutta, I., Foster, J., \& Mishra, A. (2011). On measuring vulnerability to poverty. Social Choice and Welfare, 37(4), 743-761.

Estrada, J. (2002). Systematic risk in emerging markets: The D-CAPM. Emerging Markets Review, 3, $365-379$.

Feeny, S., \& McDonald, L. (2016). Vulnerability to multidimensional poverty: Findings from households in Melanesia. The Journal of Development Studies, 52(3), 447-464.

Foster, J., Greer, J., \& Thorbecke, E. (1984). A class of decomposable poverty measures. Econometrica, 52, 761-766.

Gallardo, M. (2013). Using the downside mean-semideviation for measuring vulnerability to poverty. Economics Letters, 120(3), 416-418.

Gallardo, M. (2018). Identifying vulnerability to poverty: A critical survey. Journal of Economic Surveys. https://doi.org/10.1111/joes.12216.

Grosse, M., Harttgen, K., \& Klasen, S. (2008). Measuring pro-poor growth in non-income dimensions. World Development, 36(6), 1021-1047.

Günther, I., \& Harttgen, K. (2009). Estimating households' vulnerability to idiosyncratic and covariate shocks: A novel method applied in Madagascar. World Development, 37(7), 1222-1234.

Günther, I., \& Maier, J. (2014). Poverty, vulnerability, and reference-dependent utility. Review of Income and Wealth, 60(1), 155-181.

Hohberg, M., Landau, K., Kneib, T., Klasen, S., \& Zucchini, W. (2018). Vulnerability to poverty revisited: Flexible modeling and better predictive performance. Journal of Economic Inequality. https://doi. org/10.1007/s10888-017-9374-6.

Klasen, S. (2008). Economic growth and poverty reduction: Measurement issues using income and nonincome indicators. World Development, 36, 420-445.

Klasen, S., \& Waibel, H. (2013). Vulnerability to poverty: Theory, measurement and determinants, with case studies from Thailand and Vietnam. New York: Palgrave Macmillan.

Kolm, S. (1977). Multidimensional egalitarianisms. Quarterly Journal of Economics, 91, 1-13.

Layte, R., Nolan, B., \& Whelan, C. (2000). Targeting poverty: Lessons from monitoring Ireland's national anti-poverty strategy. Journal of Social Policy. https://doi.org/10.1017/S0047279400006073.

Ligon, E., \& Schechter, L. (2003). Measuring vulnerability. The Economic Journal, 113(486), C95-C102.

Maasoumi, E. (1986). The measurement and decomposition of multidimensional inequality. Econometrica, 54, 771-779.

Mina, C., \& Imai, K. (2016). Estimation of vulnerability to poverty using a multilevel longitudinal model: Evidence from the Philippines. The Journal of Development Studies, 53(12), 2118-2144.

Mukherjee, D. (2001). Measuring multidimensional deprivation. Mathematical Social Sciences, 42, 233-251.

Nicholas, A., \& Ray, R. (2012). Duration and persistence in multidimensional deprivation: Methodology and Australian application. The Economic Record, 88(280), 106-126.

Ogryczak, W., \& Ruszczynski, A. (1999). From stochastic dominance to mean-risk models: Semideviations as risk measures. European Journal of Operational Research, 116, 33-50.

Ogryczak, W., \& Ruszczynski, A. (2001). On consistency of stochastic dominance and mean-semideviations models. Mathematical Programming, 89, 217-232.

Oxford Poverty and Human Development Initiative. (2018). Global multidimensional Poverty Index 2018: The most detailed picture to date of the world's poorest people. Oxford: University of Oxford.

Povel, F. (2015). Measuring exposure to downside risk with an application to Thailand and Vietnam. World Development, 71, 4-24. 
Santos, M. (2019). Challenges in designing national multidimensional poverty measures. Statistics series, no. 100 (LC/TS.2019/5). Santiago: Economic Commission for Latin America and the Caribbean (ECLAC).

Santos, M., \& Villatoro, P. (2018). A multidimensional poverty index for Latin America. Review of Income and Wealth. https://doi.org/10.1111/roiw.12275.

Sen, A. (1976). Poverty: An ordinal approach to measurement. Econometrica, 44, 219-231.

Sen, A. (2003). Development as capability expansion. In S. Fukuda-Parr, et al. (Eds.), Readings in human development. New Delhi: Oxford University Press.

Tsui, K. (1995). Multidimensional generalizations of the relative and absolute indices: The AtkinsonKolm-Sen approach. Journal of Economic Theory, 67, 251-265.

Tsui, K. (2002). Multidimensional poverty indices. Social Choice and Welfare, 19, 69-93.

Youden, W. (1950). Index for rating diagnostic tests. Cancer, 3, 32-35.

Publisher's Note Springer Nature remains neutral with regard to jurisdictional claims in published maps and institutional affiliations. 